\section{Estudio arqueológico del puente de Pedret (Cercs, Barcelona)}

\section{Archaeological analysis of the bridge of Pedret (Cercs, Barcelona)}

Josep M. Vila Carabasa

Arqueociència SC. SL. Barcelona* 1

\section{Resumen}

El artículo aborda el estudio de la evolución constructiva de un puente de origen medieval, utilizando casi exclusivamente el método estratigráfico tanto en el análisis del subsuelo como en los paramentos de la estructura. El estudio ha permitido documentar la interacción entre el puente y el río con las sucesivas destrucciones y recomposiciones de la estructura, así como las mejoras que cada reparación aportaba respecto de la situación anterior.

Palabras clave: arquitectura civil; ingeniería medieval; caminos; estratigrafía vertical; arcos; riadas; comunicaciones; medieval; época moderna.

\section{Abstract}

This paper presents the constructive development of a medieval bridge using almost exclusively the stratigraphic method to analyze the subsoil and the standing structure. This work has enabled recording the interaction between the bridge and the river, including successive destructions and rebuildings of the bridge and their consecutive improvements.

Keywords: civil architecture; medieval engineering; paths; vertical stratigraphy; arches; freshet; communications; medieval; modern period.

\footnotetext{
* jmvilac@yahoo.es

${ }^{1}$ Arqueólogo colaborador del Servei de Patrimoni Arquitectònic Local. Diputación de Barcelona.
}

\section{INTRODUCCIÓN}

La investigación arqueológica sobre el Puente de Pedret se desarrolló en el marco de los estudios previos a la elaboración del proyecto de restauración y consolidación de este monumento, que llevó a cabo el año 2000 el Servei de Patrimoni Arquitectònic Local de la Diputación de Barcelona bajo la dirección del arquitecto jefe señor Antoni González Moreno-Navarro. La investigación histórica y arqueológica fue encargada a quien suscribe y supervisada por el doctor Albert López Mullor, jefe de la unidad de Investigación Histórica del referido servicio ${ }^{2}$.

\section{SITUACIÓN Y DESCRIPCIÓN}

El Puente de Pedret está situado en el municipio de Cercs, dentro de la comarca del Berguedà, en el extremo norte de la provincia de Barcelona, sobre el río Llobregat y forma parte del camino que une la población de Berga con la iglesia de San Quirze de Pedret, centro de un término documentado desde el siglo IX. Desde el punto de vista geológico, en la zona que salva el puente, el río Llobregat genera un valle estrecho, cortado en los niveles blandos y margosos del Triásico, que se alternan con calizas más duras. En la zona más cercana al cauce del río, aparecen también formaciones de conglomerados generados a partir de aportaciones aluviales.

El de Pedret se inscribe en el grupo de los puentes caracterizado por un arco central mucho más alto que el resto, también conocido como lomo de asno. Mide unos $80 \mathrm{~m}$ de largo, con dirección este oeste y está formado por cuatro arcos de luces diferentes, dos de medio punto rebajado en la ribera occidental (identificados con las u.e. 24 y 25), un tercer arco, en este caso ojival (u.e. 23), en el centro, sobre el río y finalmente un cuarto, de medio punto (u.e. 22) en el lado oriental (figs. 3-6). Todos ellos presentan una sola rosca de dovelas pequeñas de arenisca y descansan sobre pilares de sección rectangular, de 2,45; 3,3 y 2,25 m de anchura empezando por el más oriental, que descansan sobre la roca. En el lado norte disponen de tajamares desiguales de remate piramidal (fig. 21), mientras que aguas abajo, el pilar situado entre los dos arcos del lado occidental presenta un estribo perfectamente solidario de estos elementos. Por lo que se refiere a la luz, el arco más occidental tiene 3,3 m, el central 14,4 y de los otros dos, el más cercano al río 5,9 m y el último 5,6. Aguas arriba, en

\footnotetext{
${ }^{2}$ Quiero agradecer al Dr Albert López Mullor sus observaciones durante todo e proceso de elaboración del estudio original y en la redacción de este artículo. También a los evaluadores anónimos y al consejo de redacción de Arqueología de la Arquitectura sus consideraciones al texto del artículo, que espero haber sabido incorporar al redactado final.
} 

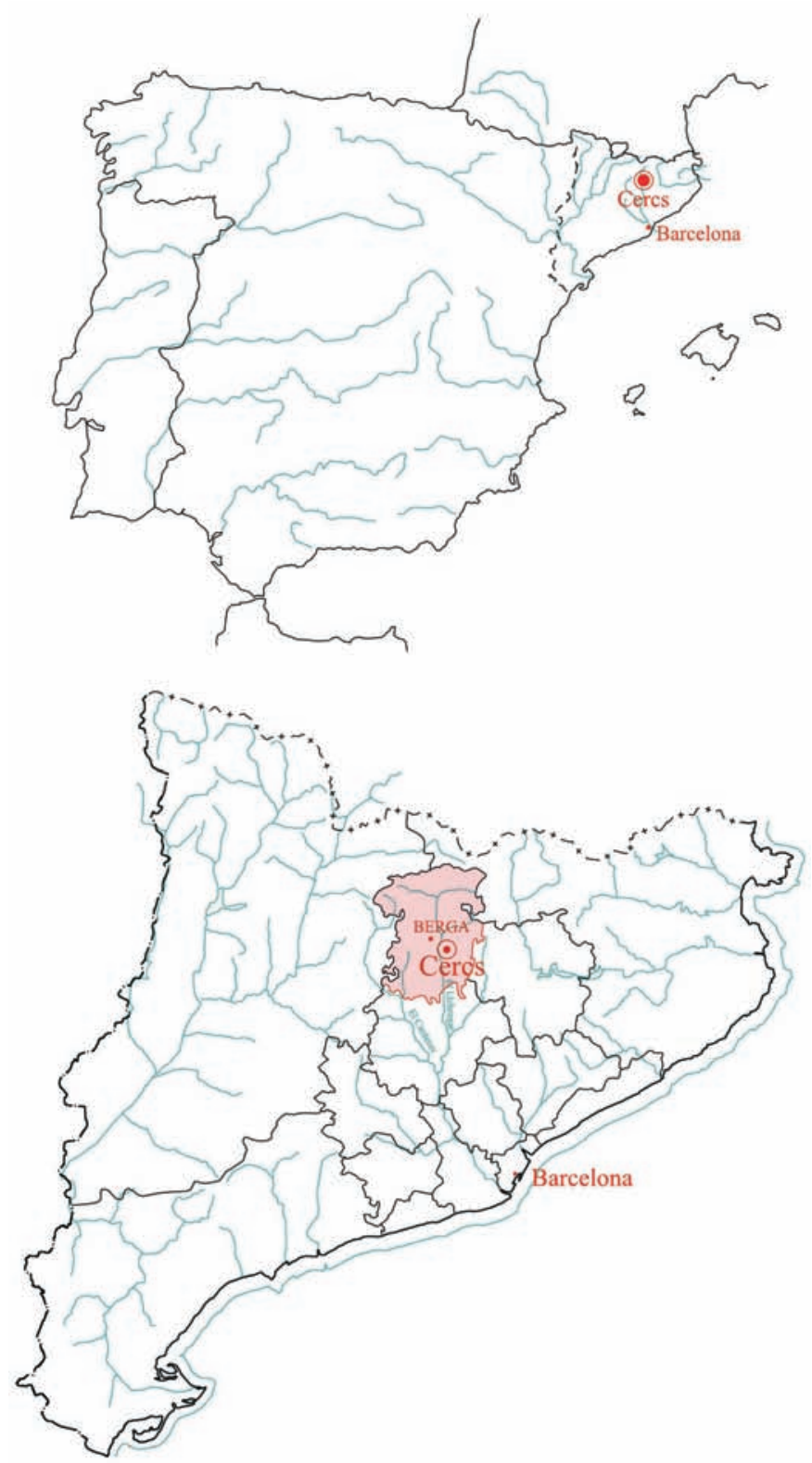

Fig. 1. Mapas de situación del municipio de Cercs donde se encuentra el puente de Pedret

el lado este, aparece un contrafuerte de sección triangular de $1,2 \mathrm{~m}$ de anchura y una altura máxima de $5,85 \mathrm{~m}$.

La caja del puente está constituida por dos muros paralelos y un relleno interno macizo hecho de bloques de piedra amorterados con cal, por lo menos en lo que se refiere al tramo central donde se sitúan los arcos. Unos sondeos arqueológicos, llevados a cabo en 1993, permitieron documentar dos pavimentos superpuestos y formados por cantos rodados que cubrían la superficie del puente (fig. 8). Es posible, aunque no se ha podido comprobar hasta el momento, que en los extremos de la estructura, más allá de la zona ocupada por el pavimento de cantos rodados y el pretil, los muros del puente sirvan simplemen- te de contención y que el espacio entre las fachadas esté relleno de tierra. La caja tiene una anchura libre de $2,35 \mathrm{~m}$ mientras que la anchura máxima de la construcción, incluyendo los pretiles, es de $3,1 \mathrm{~m}$.

Los pretiles actuales corresponden a la última fase constructiva del puente, tienen $38 \mathrm{~cm}$ de anchura y una altura en el interior de $80 \mathrm{~cm}$. Están construidos a base de mampostería y rematados con grandes losas de piedra arenisca. Presentan en la parte baja una serie de agujeros de desagüe que conducen el agua hacia el exterior de las fachadas. En el extremo oriental del guardalado se conserva una cruz grabada en la primera de las losas del pretil, que podría interpretarse bien como la reutilización para este fin de una piedra procedente de la vecina iglesia de Pedret o bien como un signo referido a una posible bendición del puente.

\section{ANTECEDENTES}

La intervención del Servei de Patrimoni Arquitectònic Local de la Diputación de Barcelona en el puente de Pedret se remonta al año 1993, momento en que se promovieron los primeros trabajos de documentación de la estructura previos a la redacción del correspondiente proyecto de restauración. Coincidiendo con estos primeros estudios, se llevó a cabo una pequeña intervención arqueológica (López Mullor, Caixal, 1993), que se centró en dos puntos de la caja del puente que en aquel momento se consideraron esenciales. El primer sondeo se abrió en el espacio comprendido entre los arranques de los dos primeros arcos, mientras que el segundo se situó más al este, cerca del límite oriental. Esta intervención permitió documentar la existencia de dos niveles de pavimento superpuestos, el más antiguo presumiblemente contemporáneo de la construcción del tramo de puente al que afectaba, mientras que el segundo, que es el que está actualmente en uso, correspondiente a una fase posterior.

En cuanto a la cronología, la intervención de 1993 no permitió recuperar ningún tipo de material arqueológico. En todo caso, la similitud morfológica del pavimento de la segunda fase con otro que se documentó en el puente de Castellbell i el Vilar (Caballero, 1991) y que se había podido situar entre los siglos XVI y XVII, permitió apuntar a los autores de la intervención que el pavimento de Pedret también podría pertenecer a ese mismo momento cronológico.

\section{PLANTEAMIENTO Y MÉTODO}

El Servei de Patrimoni Arquitectònic Local de la Diputación de Barcelona ha llevado a cabo a lo largo de los últimos 25 años numerosas intervenciones de restauración en puentes de las cuencas fluviales que discurren por la pro- 


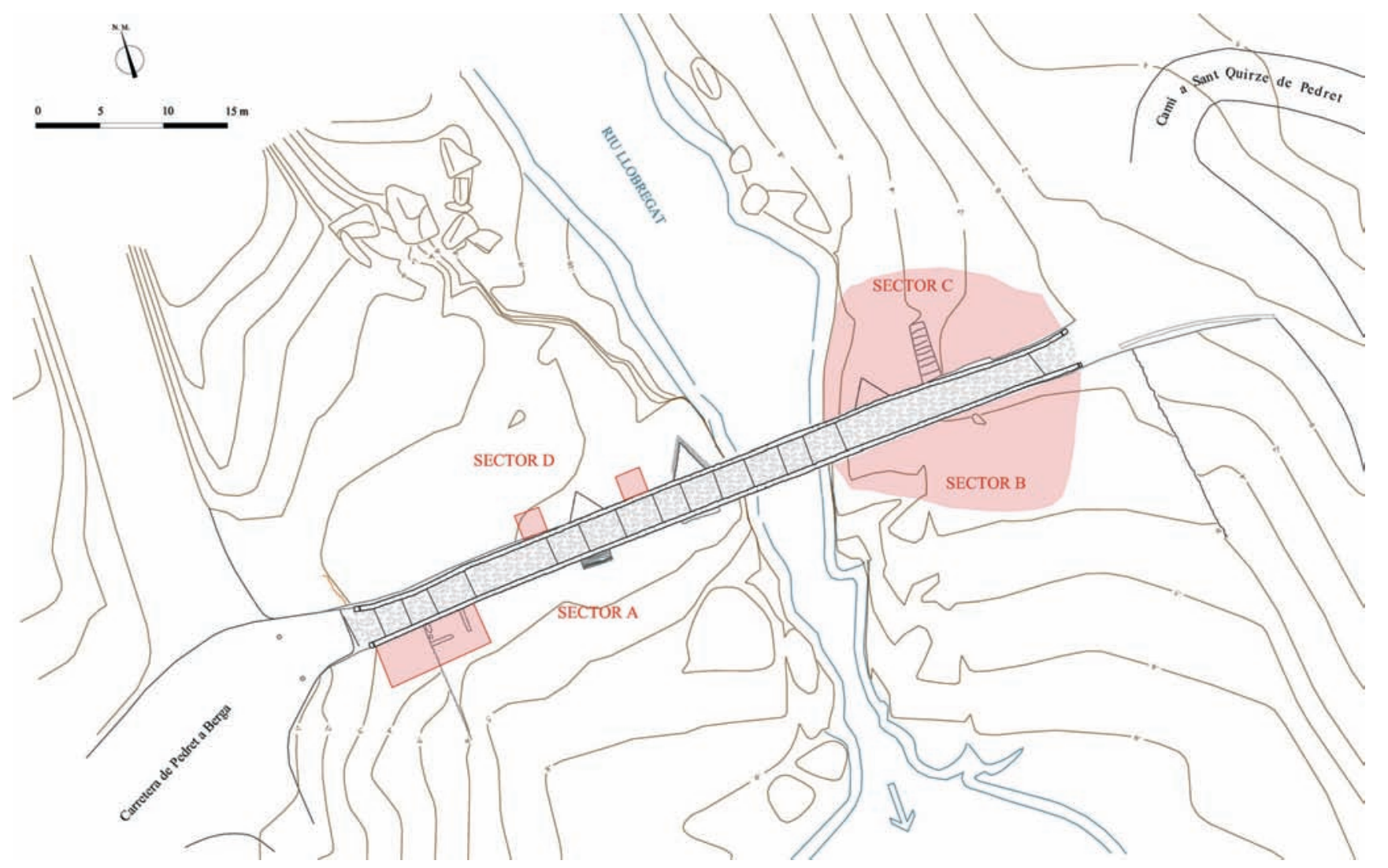

Fig. 2. Planta topográfica del puente con la situación de las estructuras aparecidas en el transcurso de la intervención arqueológica

vincia (Caixal 1986). Esta experiencia ha permitido a sus responsables perfeccionar un método de análisis histórico y arqueológico específico para este tipo de estructuras que es el que nosotros hemos aplicado a nuestro estudio. La investigación arqueológica en el puente de Pedret se desarrolló en dos ámbitos. En primer lugar, la excavación arqueológica de las tierras que circundaban la base del puente. Su objetivo era localizar niveles asociados al momento de construcción de la estructura, con el fin de aproximarnos, si era posible, a su datación absoluta. En segundo lugar y de manera paralela a la excavación, se planteó un estudio arqueológico de los paramentos del puente de cara a la constatación de las sucesivas fases constructivas, destrucciones y reparaciones de que había sido objeto.

Para el registro de los datos que facilitaron el conjunto de los trabajos realizados utilizamos el sistema propuesto por E.C. Harris y por A. Carandini, modificado a partir de la práctica arqueológica en este tipo de estructuras y de las circunstancias concretas del estudio. Para el registro objetivo de los elementos y estratos se realizó una numeración correlativa de los mismos a los que se denominó unidades estratigráficas (u.e.). De cada una de ellas se hizo una ficha en la que se indicaba: la situación en el contexto general de la estructura, la ubicación en las plantas y secciones, la definición y la posición física respecto de las otras unidades estratigráficas. Este sistema se utilizó de manera indistinta para la excavación del subsuelo y para el estudio de paramentos, quedando referenciadas todas las u.e. en una lista única que permite relacionar las estructuras del puente entre sí y con los elementos y estratos documentados durante la excavación de su entorno.

El material gráfico elaborado está compuesto por plantas generales y de detalles concretos que aportan una visión sincrónica de las fases del yacimiento, secciones en las que se representa la sucesión estratigráfica que facilita la comprensión diacrónica de su evolución; alzados de los muros para la representación y estudio de las fases constructivas del puente, así como el material fotográfico imprescindible para la constancia visual de los trabajos llevados a cabo y de las evidencias arqueológicas detectadas.

\section{DESARROLLO DE LOS TRABAJOS}

\section{Excavación arqueológica}

Dada la estructura del espacio, muy condicionada por la presencia del puente y del río, se decidió dividir el área de la excavación en cuatro sectores (fig. 2). 
- Sector A: Aguas abajo, ribera oeste.

- Sector B: Aguas abajo, ribera este.

- Sector C: Aguas arriba, ribera este.

- Sector D: Aguas arriba, ribera oeste.

A la vista de las diferencias en la estratigrafía documentada en cada uno de los sectores estudiados, procederemos a su exposición de manera independiente.

\section{Sector A}

En el momento de iniciarse la intervención, toda el área situada aguas abajo del puente en el costado occidental, a excepción del sector más cercano al río donde afloraba la roca, se hallaba cubierta por un estrato de arcillas con componentes vegetales y bloques de piedra caliza y conglomerados (u.e. 5). Este estrato aparecía en forma de talud en dirección oeste a causa de la mayor aportación de tierras procedentes de la erosión de la montaña y cubría una serie de estructuras adosadas a la pared del puente (fig. 11). En un punto concreto se iniciaba la falda de la montaña propiamente dicha, que en este sector no presentaba una inclinación uniforme sino que el diferencial de dureza entre las capas de roca caliza y margas que componen el substrato habían generado una pendiente escalonada (fig. 22). La intervención consistió en la excavación extensiva de la zona ocupada por las estructuras, así como en la eliminación de los niveles superficiales en la zona más cercana al puente, con la finalidad de delimitar completamente su trazado y tratar de identificar su arranque.

La excavación del nivel superficial permitió documentar, al menos parcialmente, el trazado de las estructuras que se insinuaban en el momento de iniciarse la intervención.
Se trataba del muro u.e. 9, de $40 \mathrm{~cm}$ de anchura, perpendicular al puente y hecho con aparejo de bloques de arenisca y conglomerado, de diferentes medidas, dispuestos de manera aleatoria y unidos con tierra. Era solidario de un segundo muro (u.e. 10), paralelo al puente, de similares características constructivas, aunque mucho más arrasado y que parecía adosarse a un recorte en el talud de la montaña. Estos dos muros, junto con la pared del puente y el recorte en el terreno, generaban una pequeña estancia de $3 \times 4,5 \mathrm{~m}$ aproximadamente. La excavación del interior de este espacio, que se denominó habitación 2, permitió delimitar un único nivel de relleno por debajo del superficial. De trataba de un estrato (u.e. 16) formado por arcillas y limos rojizos, bastante compactos y en cuya superficie de detectaron pequeños carbones y manchas cenicientas, que permitían identificarlo como el nivel de uso de la habitación.

A unos $3 \mathrm{~m}$ al este del muro 9, y paralelo a éste, se documentaba el muro u.e. 8 , de $55 \mathrm{~cm}$ de anchura, muy arrasado y formado por bloques de piedra unidos con tierra. El sector situado entre los muros 8 y 9 se denominó habitación 1 y estaba dividido en dos ámbitos por un muro formado por losas de piedra colocadas verticalmente (fig. 11). Su estratigrafía era similar a la de la habitación 2.

Finalmente, el estudio de paramentos del puente en el tramo en el que se adosan estas estructuras permitió obtener algunos datos complementarios, referidos fundamentalmente a la configuración en altura de estas habitaciones. Sabemos que los muros estudiados se adosan a una importante reparación de la fachada del muro del puente, con la construcción de un revestimiento de mampostería (u.e. 15) al que se asocian cuatro mechinales (u.e. 26) situados a 2,65 $\mathrm{m}$ del suelo. Un poco más arriba, a unos

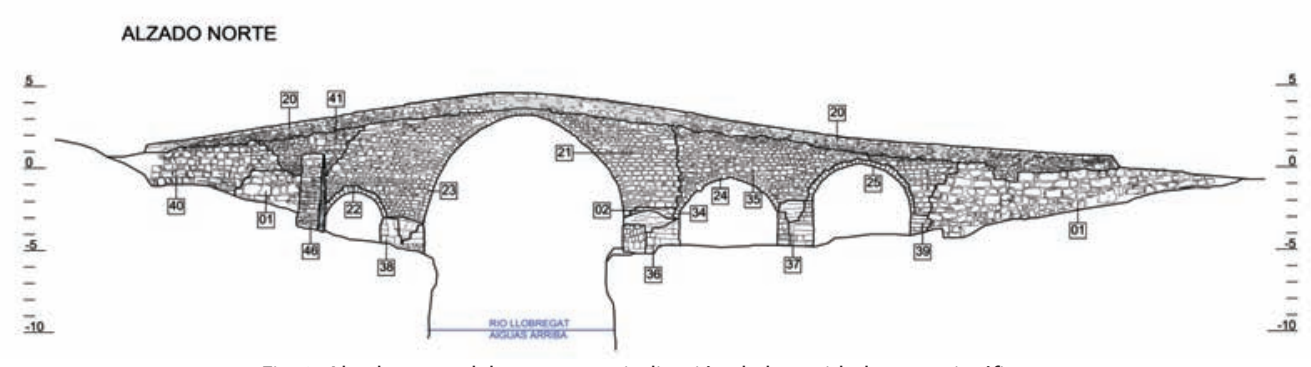

Fig. 3. Alzado norte del puente con indicación de las unidades estratigráficas

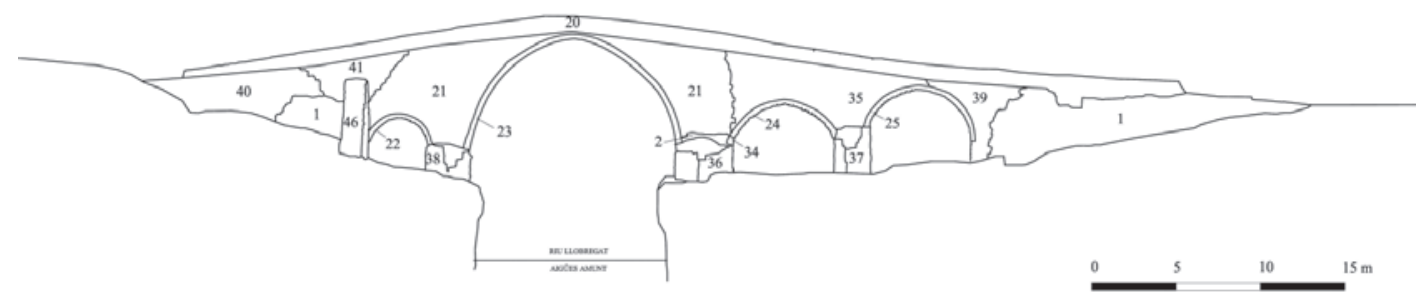

Fig. 4. Croquis del alzado norte del puente con indicación de las unidades estratigráficas 


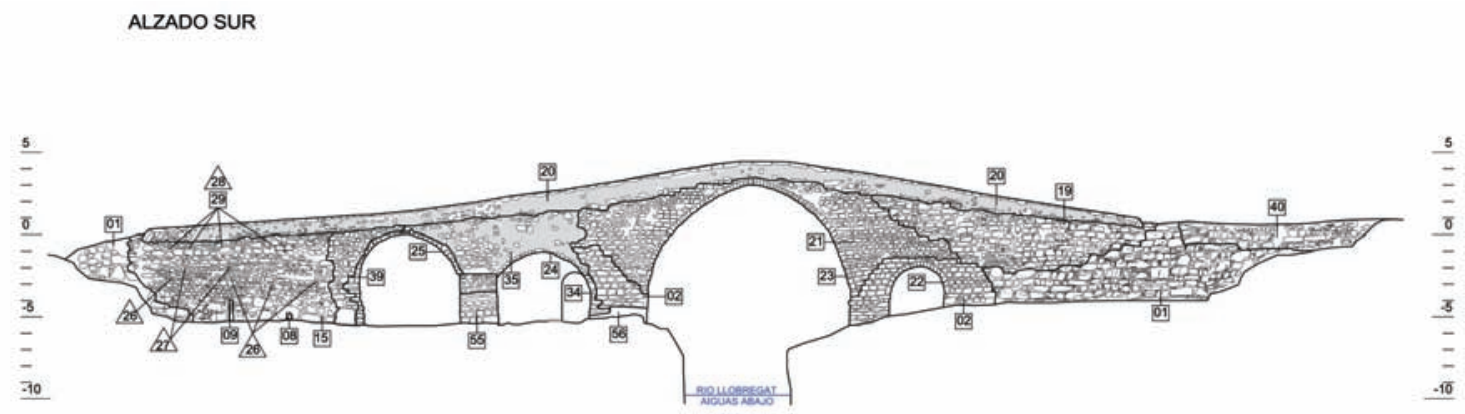

Fig. 5. Alzado sur del puente con indicación de las unidades estratigráficas

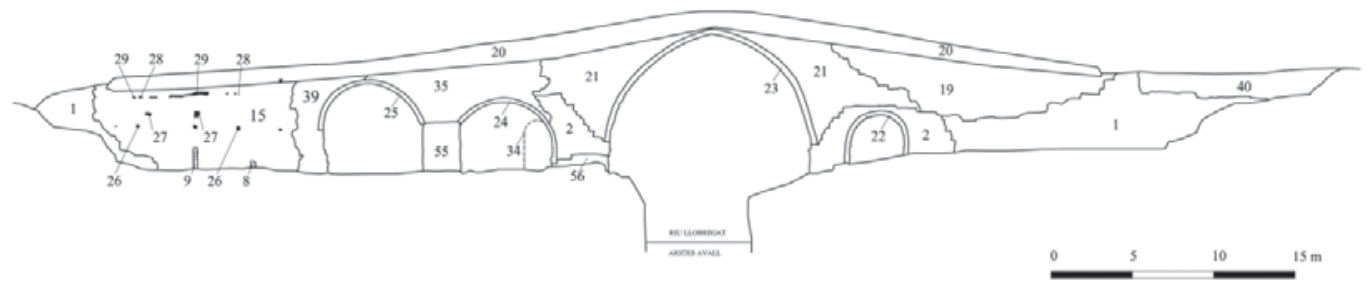

Fig. 6. Croquis del alzado sur del puente con indicación de las unidades estratigráficas

3,15 m del arranque del muro, se identificaron dos grandes agujeros cuadrados (u.e. 27) de $40 \mathrm{~cm}$ de lado, posteriores a la construcción del revestimiento u.e. 15 y que habrían servido de apoyo las vigas que sostenían la cubierta de las habitaciones adosadas. Finalmente, a unos $5,25 \mathrm{~m}$ por encima del suelo, se documentaron restos del mortero (u.e. 29) que habría unido la cubierta de la habitación a la pared del puente. Asociados a este mortero se documentaron una serie de pequeños agujeros ovalados (u.e. 28) que parecen corresponder a los encajes de las vigas que sustentaban el tejado de la construcción (fig. 18).

Por lo que se refiere a la delimitación del perímetro del puente, la excavación del nivel superficial permitió comprobar que la estructura se apoya directamente sobre la roca y que su estribo se adosa, escalonadamente, a la falda de la montaña.

\section{Interpretación}

La intervención arqueológica permitió comprobar que el sector A corresponde a la zona más resguardada respecto de las inundaciones ya que se encuentra protegida por el puente y por la propia pendiente de la montaña que crece de cota en dirección oeste y norte, lo que hace que el agua tienda a desplazarse hacia el lado oriental, al sector B. En esta zona se construyó una barraca adosada al puente y a la falda de la montaña y en la que se han detectado dos fases constructivas.

En una primera fase el cobertizo (habitación 1) estaría delimitado por el lado este por el muro 8 y al sur por un hi- potético muro solidario de éste y que seguramente estaría un poco más avanzado de lo que posteriormente sería el trazado de u.e. 10. Estas paredes se apoyaban directamente en la roca y el interior del perímetro que delimitaban se regularizó con tierra, generando los niveles 7 y 16, la superficie de los cuales funcionaría como nivel de circulación. La cubierta era de tejas sobre vigas apoyadas contra la pared del puente. En un momento que debemos situar seguramente a principios del siglo XX se produjo el abandono de la cabaña, de la que sólo quedaron en pie los restos del muro 8 .

Hacia 1905, se construyó un segundo cobertizo (habitación 2), más pequeño, y definido por los muros 9 y 10. Esta edificación, asentada en buena parte sobre el relleno 16 ligeramente recortado, utilizaba como pavimento la nueva superficie del estrato 16 y estaba cubierta por un tejado similar al de la anterior aunque situado a una cota más baja en la pared del puente. Los datos sobre la cronología y cubierta de esta segunda cabaña se desprenden de una fotografía del puente, tomada por Cèsar August Torras en torno a $1905^{3}$, en la que aparece una esquina del tejado, así como señales en la pared del puente correspondientes a la cubierta anterior.

\section{Sector B}

La intervención consistió en la excavación de las tierras de la zona más cercana al río, con el fin de delimitar el

3 Archivo Fotográfico del Servei de Patrimoni Arquitectònic Local. Fondo SCCM. Ficha número 22.904 


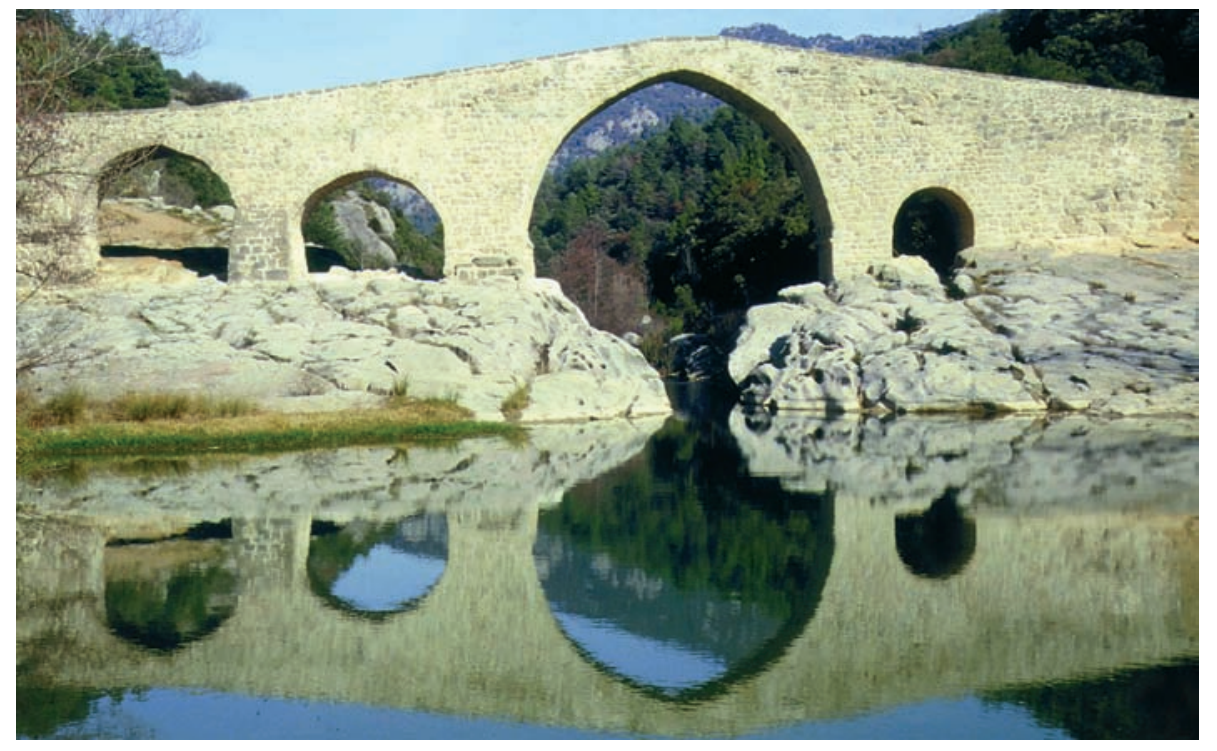

Fig. 7. Vista frontal del lado meridional del puente. Foto: M. Baldomà, 2001. Archivo fotográfico Servei del Patrimoni Arquitectònic Local de la Diputació de Barcelona (en adelante SPAL) perímetro del puente y localizar posibles niveles asociados a la construcción de la estructura. En el momento de comenzar, toda la zona se encontraba cubierta por un nivel

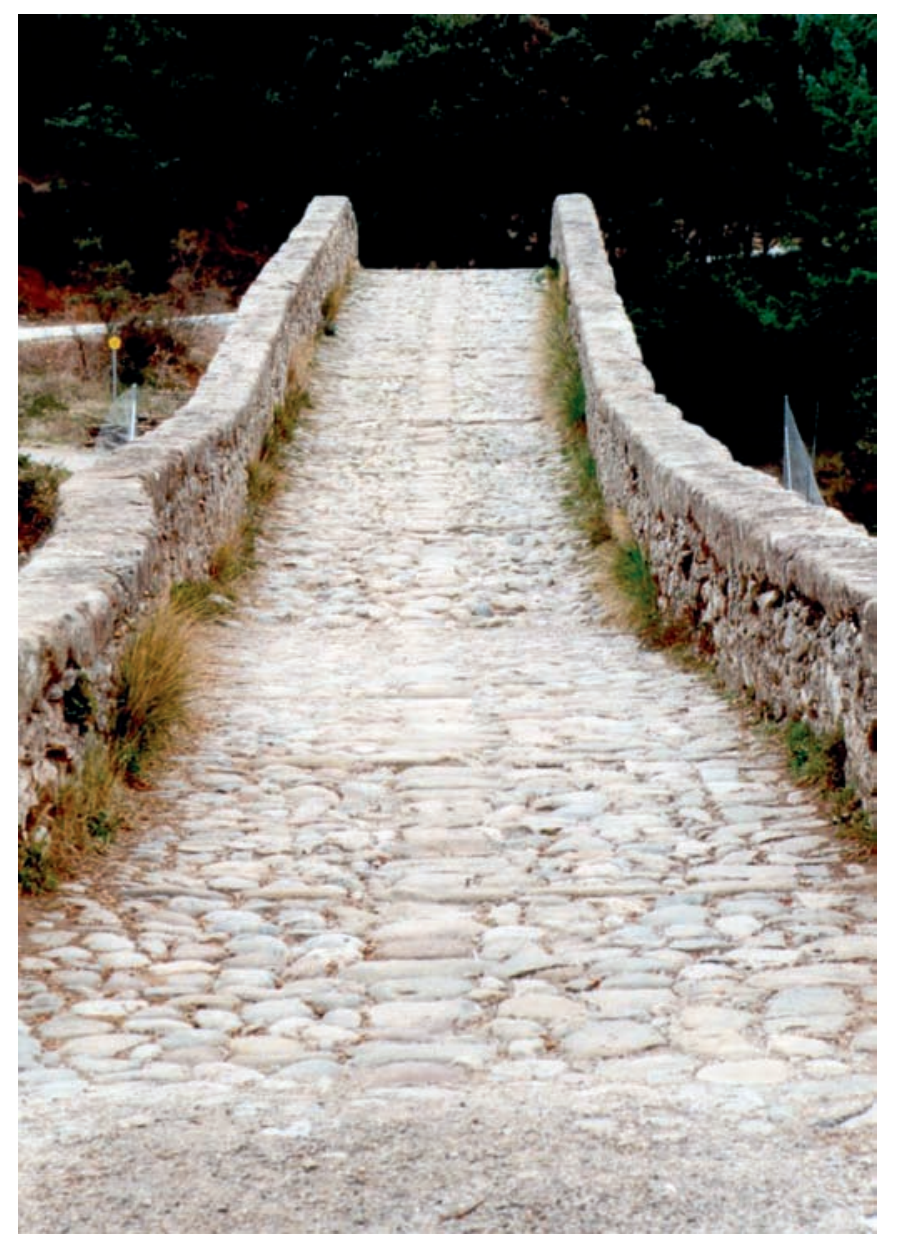

Fig. 8. Vista del pavimento actual del puente. Foto: Josep M. Vila, 2000. Archivo fotográfico SPAL (u.e. 3) formado por tierras y bloques de piedra de tamaño mediano-grande, a excepción de la zona más cercana al río donde aparecía la roca. Este estrato, formado fundamentalmente por aportaciones de la erosión de la montaña circundante, estaba dispuesto en un talud que moría junto al río. Bajo este nivel, en el lado oeste aparecía la roca, mientras que en el sector más cercano a la ribera se documentaba un estrato formado por tierras mezcladas con gravas y arena (u.e. 33) en el que se recuperaron algunos fragmentos de cerámica de la fábrica Pickman, que aportan un terminus post quem de siglo XIX avanzado para la formación de este estrato. En el punto en que se iniciaba la pendiente de la montaña aparecieron los restos de un muro (u.e. 43) hecho con grandes cantos de piedra caliza y conglomerados, así como algún bloque de piedra más pequeño, unidos con tierra (fig. 9) y que parecía servir de contención para las tierras de la falda de la montaña. Sólo se conservaba un tramo de unos 3,6 m de largo junto al muro del puente y parecía perder consistencia a medida que se alejaba de éste. La excavación de los niveles situados tras 43 permitió constatar que a partir de la línea de este muro de iniciaba la falda de la montaña, sobre la que se asentaba también el puente. Ello parece explicar la construcción del muro 43 que impedía que la erosión dejara a la vista la cimentación del puente poniendo en peligro su estabilidad.

En el espacio situado entre el muro 43 y el río, bajo el estrato 33, aparecía el sustrato geológico en la mayor parte del sector. En todo caso, y rellenando una depresión natural de la roca, se localizó un estrato (u.e. 04) formado por arcillas y limos de color rojizo. En él se recuperó un lote de cerámica gris medieval seguramente producida en 


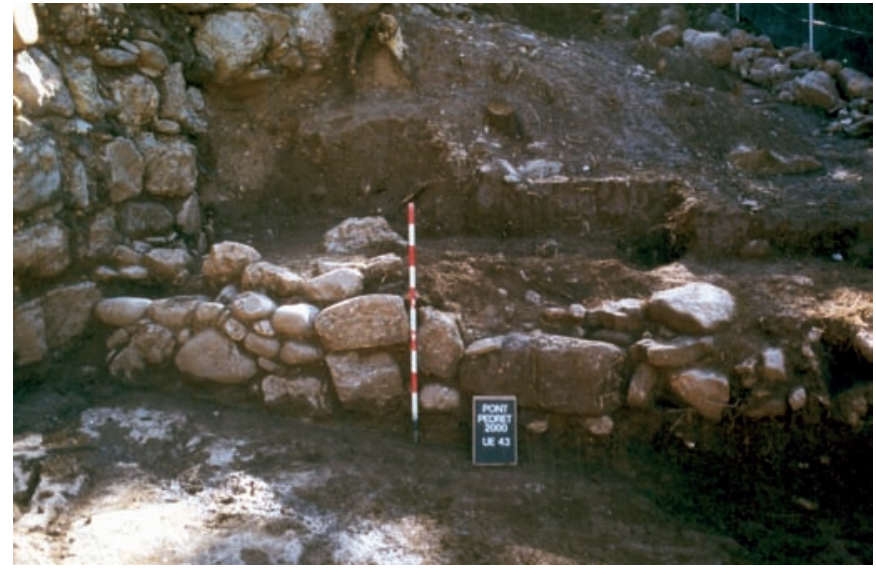

Fig. 9. Vista general del muro de contención u.e. 43. Foto: Josep M. Vila, 2000. Archivo fotográfico SPAL

el cercano taller medieval de Casa-en-Ponç (Berga). Por debajo se documentaba en algunos tramos un estrato de arena rojiza y grava (u.e. 12) que completaba el relleno de esta depresión y en el que también se recuperaron, aunque en menor número, algunos materiales de la misma procedencia.

\section{Interpretación}

Dentro del yacimiento se trata del sector en el que se documenta una menor potencia de sedimento ya que, a causa de la pendiente natural de la roca, en caso de avenida el agua que sale por los ojos del puente tiende a desviarse hacia el lado oriental, produciéndose una mayor limpieza por arrastre del sedimento depositado en aquella parte. Ello ha provocado que la estratificación documentada corresponda fundamentalmente a materiales aportados en la última inundación que tuvo lugar entre finales del siglo XIX y los años 70 del siglo XX. Desde esta última fecha, la construcción de una presa aguas arriba del puente evita las crecidas repentinas del río. Sobre este depósito, formado por las gravas u.e. 33 se ha ido generando la capa u.e. 3 de tierras arcillosas procedente de la erosión de la montaña. En cualquier caso, la existencia de una pequeña depresión o cubeta en la roca del cauce del río ha permitido conservar en su interior un estrato de limos (u.e. 4) cuya deposición, a juzgar por los materiales que contiene, se ha de situar en el siglo XIII. Aunque no existe una relación física directa entre este nivel y el puente, su cronología y la abundancia de material cerámico asociado parecen relacionarlo con un momento de actividad constructiva de la estructura.

En lo que se refiere a su cimentación, el puente se apoya directamente en la roca en todo el espacio central. Con todo, su estribo oriental se adosa a las tierras de la falda de la montaña, siguiendo una pendiente ascendente

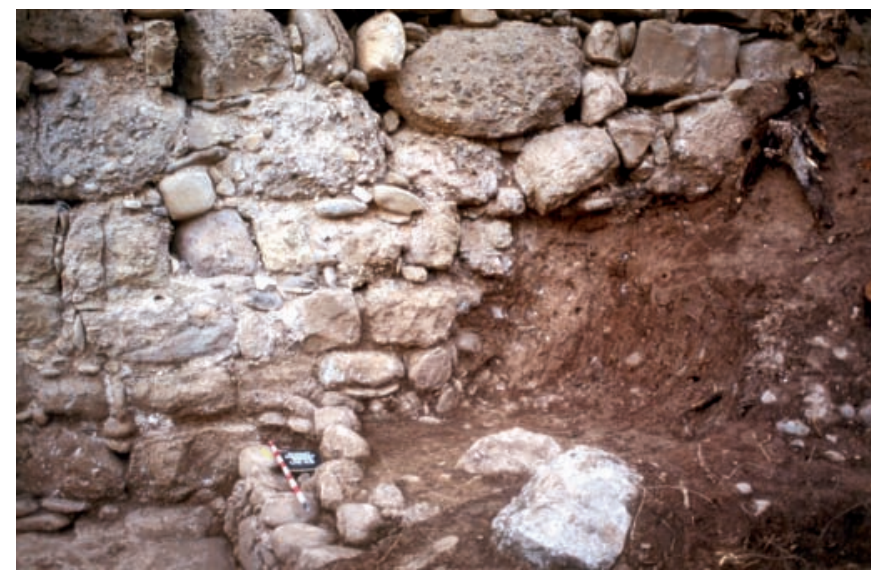

Fig. 10. Detalle del asentamiento del estribo oriental del puente en la falda de la montaña. Foto: Josep M. Vila, 2000. Archivo fotográfico SPAL

(fig. 10). Este sistema genera una cierta debilidad constructiva en este punto donde incidirían procesos erosivos de dos tipos. Por una parte, los generados por las aguas de lluvia que limpiarían la falda de la montaña, descalzando la cimentación. Por otra parte, las avenidas, que arrastrarían la parte baja del talud natural. Con el fin de proteger este punto, se optó por la construcción del muro u.e. 43, en la parte más cercana al puente, que servia a la vez de contención de las tierras arrastradas por la lluvia y de protección contra la acción del agua de las riadas.

\section{Sector C}

El sector noroeste del puente presentaba una importante acumulación de tierra procedente en su mayor parte de la erosión de la falda de la montaña, que fue mayoritariamente extraída por medios mecánicos. La intervención permitió confirmar que la cimentación del puente se apoya directamente sobre la roca, que sigue una suave pendiente en dirección sur este. También se pudo estudiar la cimentación del contrafuerte adosado a la pared del puente (u.e. 46), observándose que se apoyaba en parte en la roca natural y en parte en el sedimento de tierra aportada por el río.

Parece claro que éste es el sector que más ha sufrido los efectos de la erosión, tanto de carácter atmosférico como por inundación, como lo demuestran las importantes reparaciones detectadas en esta cara del puente. La construcción del gran contrafuerte (fig. 19) produjo importantes cambios en este espacio, ya que aparte de impedir el desprendimiento de la fachada norte, sirvió de muro de contención para los sedimentos arrastrados por la lluvia desde la montaña. Ello provocó la actual acumulación de tierras, que ha deformado ligeramente el trazado del área final del puente, el límite del cual ha quedado cubierto por las tierras y después transformado por la construcción del 
camino de acceso para vehículos de la cercana iglesia de Sant Quirze de Pedret.

\section{Sector D}

La zona noroeste del puente presenta una pendiente natural en dirección norte y oeste, generándose una plataforma inclinada, cortada en su lado oriental por el curso del río, mientras que su límite occidental enlaza con la falda de la montaña. El sector se encontraba cubierto por un nivel de tierras (u.e. 5) generado por las aportaciones de carácter pluvial procedentes de la montaña y que cubría el substrato natural. Este nivel tenía una potencia que oscilaba entre los $40 \mathrm{~cm}$ del lado más occidental hasta desaparecer en el extremo oriental. Vista la extensión y características de este estrato se optó por su excavación mecánica. Con posterioridad se hicieron dos sondeos junto a la pared del puente para determinar la potencia estratigráfica y el tipo de sedimento que se localizaba por debajo de este nivel superficial. En ambos casos se documentaron diversas capas de limos aportadas en sucesivas crecidas del río. Debajo de ellas se identificó una acumulación de piedras de mediano y pequeño tamaño que rellenaban el desnivel de la roca en la zona más cercana al puente (u.e. 50).

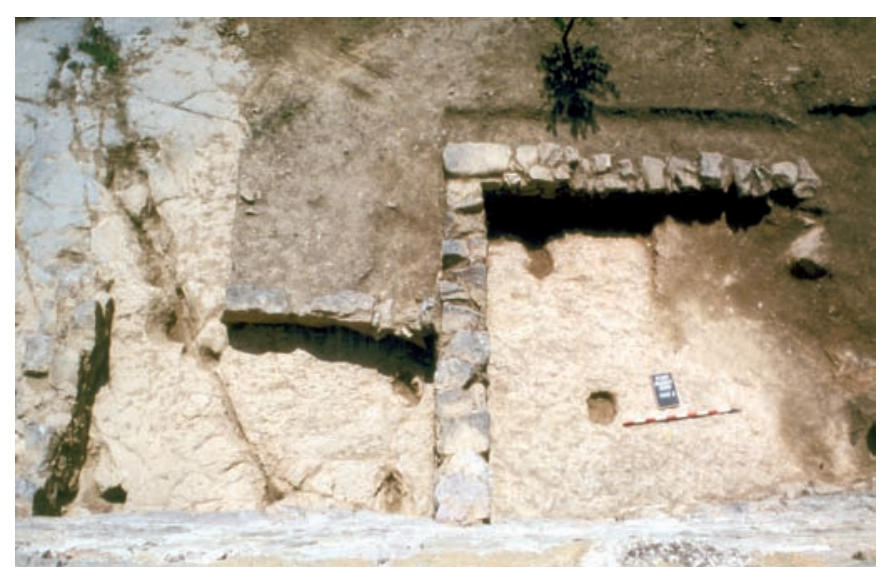

Fig. 11. Vista superior de las estructuras adosadas al puente que se documentaron en el transcurso de la excavación del sector B. Foto: Josep M. Vila, 2000. Archivo fotográfico SPAL

\section{Interpretación}

El sector D corresponde a una de las zonas menos afectadas por la acción directa del agua de las avenidas ya que está protegida por un espigón natural que en el lado más cercano al río se eleva hasta una cota similar a la de la parte superior del puente. Así, y como una especie de tajamar natural, evita la acción directa de la corriente del río sobre la estructura. Ello ha provocado en primer lugar una mejor conservación del puente, que no se ha visto afectado por la acción mecánica de las riadas, aunque sí por el crecimiento del nivel del agua, hecho que explica que las juntas de las piedras hayan perdido completamente el mortero que las unía.

También como consecuencia de este hecho, la mayor parte de los sedimentos aluviales que se han ido depositando delante del muro en el transcurso de las sucesivas avenidas son arenas o limos y no guijarros o gravas de mayor tamaño. La acumulación de bloques representada por el estrato 50 no parece tener un origen aluvial, sino constructivo, generado en el transcurso de alguna de las reformas del puente, probablemente la construcción del arco 25. Por encima de los niveles claramente aportados por el río aparecen los estratos generados por la erosión de la montaña (u.e. 5 y 30), que acaban de configurar el perfil orográfico del sector.

\section{ESTUDIO DE PARAMENTOS}

La fábrica del puente es relativamente heterogénea y se pueden detectar trazas de diferentes reparaciones y reconstrucciones, que describiremos a continuación de manera diferenciada según la fachada.

\section{Descripción de la fachada sur (figs. 5 y 6)}

La fachada meridional del puente es la que presenta una mayor extensión de pared vista (unos $80 \mathrm{~m}$ lineales). En ella se detectan diversos cambios en el paramento que serían el reflejo de sucesivas reparaciones del puente.

\section{Paramento u.e. 1}

Aparece en los dos extremos de la estructura y está constituido por grandes bloques de conglomerado, arenisca y piedra caliza sin desbastar de entre 110 × 70 y 40 × 30 $\mathrm{cm}$, acuñados con otros más pequeños, normalmente cantos rodados, que se disponen de manera irregular, aunque con tendencia a marcar hiladas (fig. 12). El aparejo presenta a menudo bloques más pequeños en la parte baja del muro y mayores en la alta (fig. 14). Están unidos con mortero de cal que se ha conservado de manera irregular a causa de una mayor o menor incidencia de los factores erosivos en cada zona del puente. Respecto a la procedencia de los bloques, todos ellos se encuentran de manera natural en el entorno inmediato de la estructura.

Desde el punto de vista estratigráfico, este paramento se apoya siempre sobre la roca o sobre la falda de la montaña y en ningún caso sobre otros elementos construidos. Se le adosan los niveles de tierra u.e. 33 y las estructuras (muro 43) situadas en el exterior del puente, así como el resto de paramentos con los que tiene contacto. 
Fig. 12. Detalle del paramento del puente en el sector C. Foto: Josep M. Vila, 2000. Archivo fotográfico SPAL
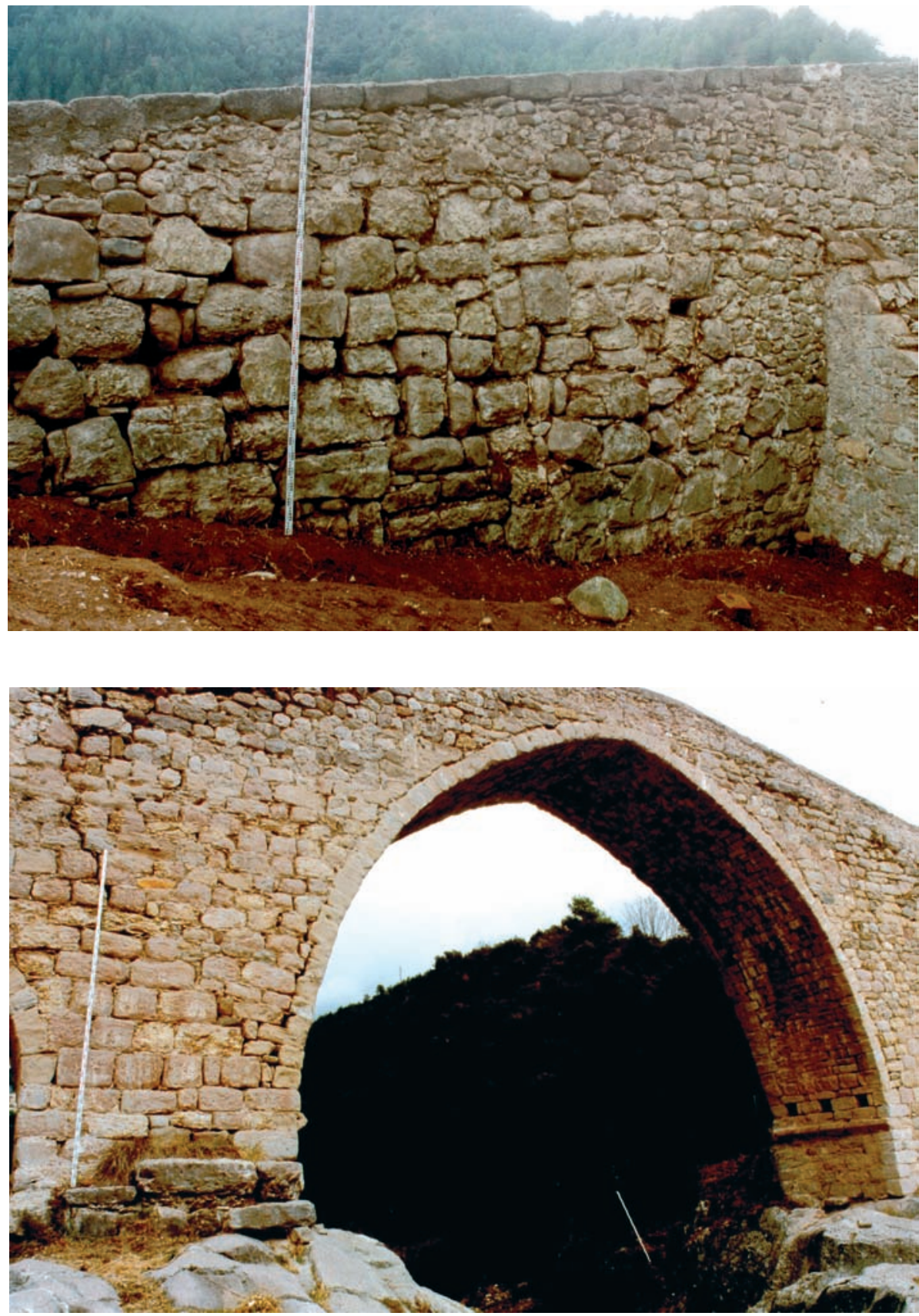

Fig. 13. Vista general del arco central del puente. Foto: Josep M. Vila, 2000. Archivo fotográfico SPA
Estas relaciones estratigráficas permiten suponer que el muro u.e. 1 corresponde a la parte más antigua de las conservadas del puente.

Respecto a las estructuras asociadas, no hay relación física en esta fachada con ninguno de los arcos Lo más probable, a la vista de la posición relativa de las estructuras, es que sea coetáneo del arco más occidental. Este elemento presenta dos fases constructivas. La primera (u.e. 22) la constituye la parte interna del arco, construido a base de bloques medianos de piedra, muchos de los cuales son cantos rodados partidos por la mitad para poder presentar una cara más o menos plana, unidos con mortero de cal de color marrón. La estructura parece haber sido construida mediante encofrado, siguiendo un sistema similar al de las bóvedas. Es probable que a esta fase correspondan unos arcos exteriores con rosca formada por cantos alargados, hoy desaparecidos.

En una segunda fase se substituyeron los arcos exteriores por los que se conservan hoy en día (u.e. 44), formados por dovelas de piedra arenisca rosada. También parece corresponder a esta misma fase una cimentación (u.e. 56) situada en la parte baja de la imposta occidental del arco central. 

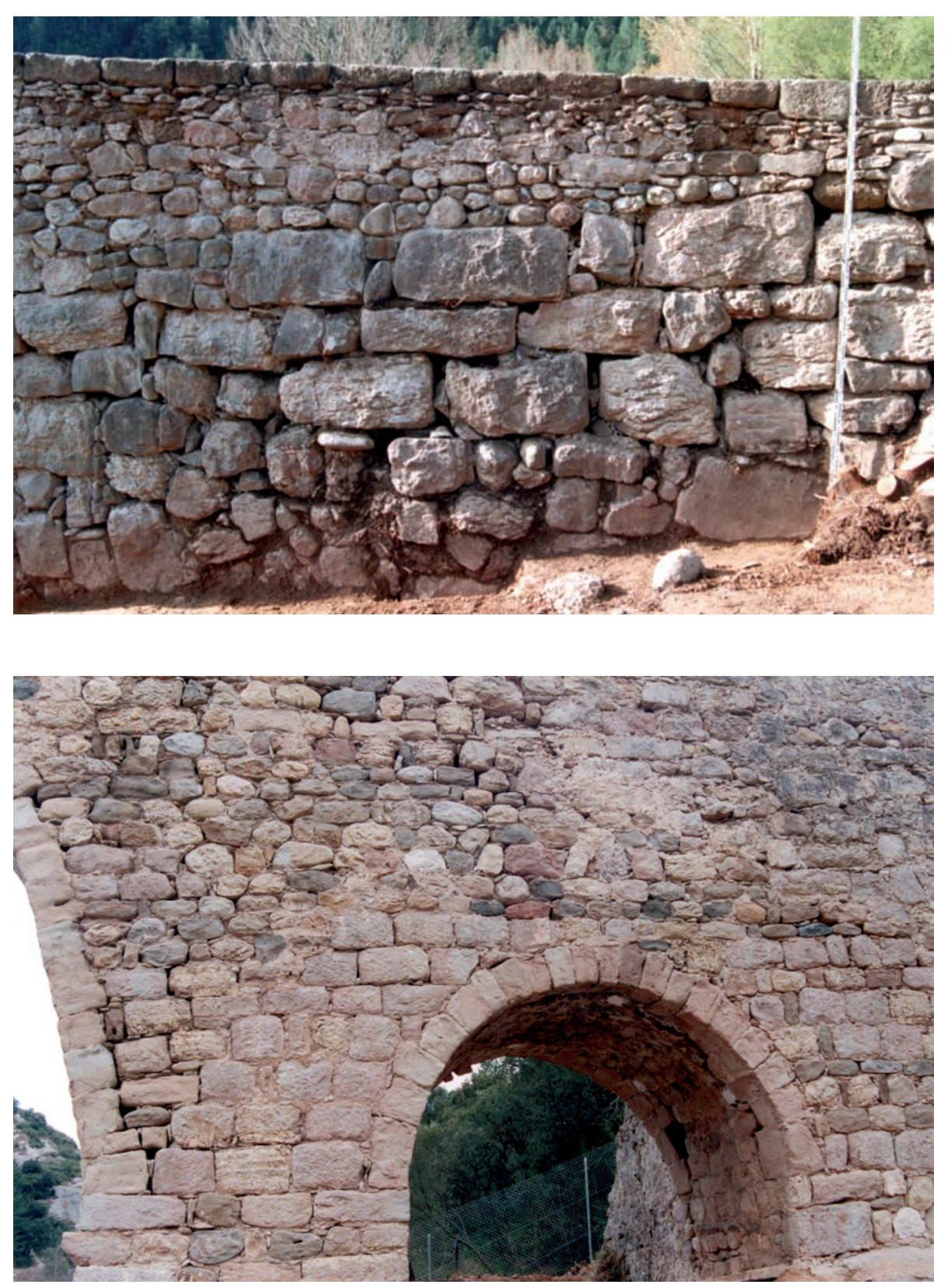

Fig. 14. Vista general del paramento u.e. 1. Foto: Josep M. Vila, 2000. Archivo fotográfico SPAL
Fig. 15. Vista del paramento u.e. 2 entorno del arco 22 con la rosca construida en la fase II. Foto: Josep M. Vila, 2000. Archivo fotográfico SPAL

\section{Paramento u.e. 2}

Se conserva en la parte baja del centro de la estructura. Está constituido por hiladas regulares de sillarejo de piedra arenisca roja unidos con cal. En algunos intervalos presenta alineaciones de bloques más pequeños, sin retocar y constituidos fundamentalmente por cantos de río. $\mathrm{Se}$ le asocian constructivamente el arco u.e. 44 y los basamentos del central (u.e. 56) y de 34. También le corresponden el arranque del arco 34 formado por una rosca de dovelas cuadrangulares de piedra arenisca clara, a diferencia de las del arco 24 que son rojizas (fig. 16). El intradós está construido a base de sillares rectangulares de tamaño mediano y grande de piedra de diferentes tipos (arenisca roja y clara...) unidos con mortero de cal muy compacto. Este arco parece que originariamente tenia una luz mucho más pequeña que 24 y probablemente corresponde a su basamento occidental una morterada de piedras y cal (u.e. 42) documentada en el suelo del actual arco 24.

Estratigráficamente este paramento se adosa claramente al tramo más antiguo del puente (u.e. 1), mientras que el resto de elementos con los que tiene contacto físico son posteriores. De ello se desprende que corresponda a una segunda fase constructiva del puente. 


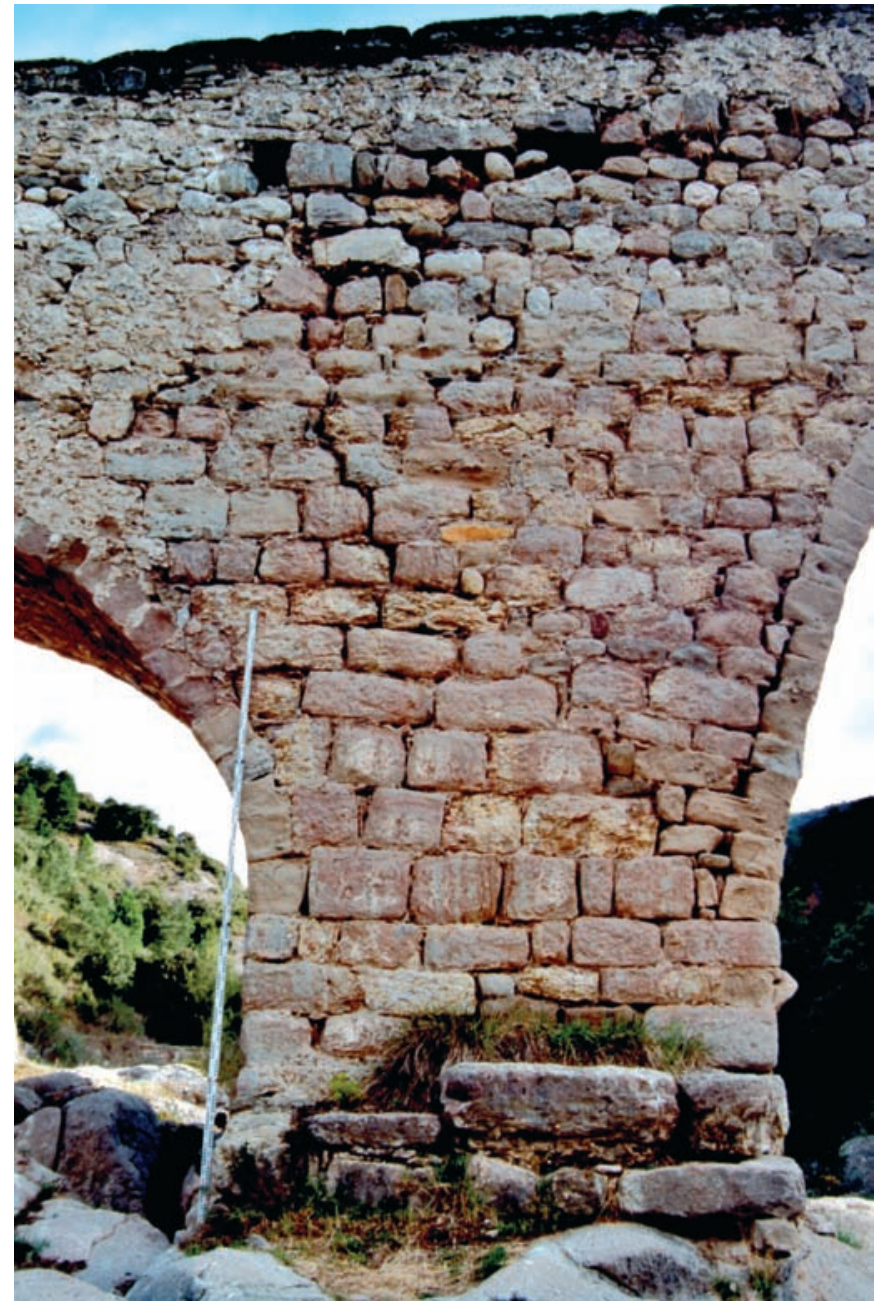

Fig. 16. Detalle del pilar de separación entre el arco central y el occidental. Se observa, a parte del paramento u.e. 2, el arranque del arco 34 y el antiguo basamento u.e. 56 correspondiente a la fase 1. Foto: Josep M. Vila, 2000. Archivo fotográfico SPAL

\section{Paramento u.e. 21}

Se trata fundamentalmente del tramo asociado a la construcción del arco central del puente. Está formado por bloques de piedra de diferentes tipos, tanto sillarejo de arenisca o conglomerado como cantos rodados partidos, todos ellos dispuestos en hiladas irregulares y unidos con mortero de cal muy compacto (fig. 13). Parece que se debió construir en buena parte aprovechando materiales antiguos que fueron recolocados, completándose la obra con cantos de río. Esta composición del muro disimula en parte la uniformidad del aparejo que puede cambiar mucho de aspecto en función de una mayor o menor presencia del sillarejo en su composición.

En cuanto a las estructuras asociadas, este paramento es claramente solidario del arco central del puente y probablemente contemporáneo de la construcción del tajamar u.e. 38 situado entre los $\operatorname{arcos} 22$ y 23 . Por lo que se refiere a su posición física, se apoya claramente en el paramento u.e. 2, mientras que el resto de estructuras con las que tiene contacto es claramente posterior. Parece corresponder, por tanto, a una tercera fase constructiva del puente.

\section{Paramento u.e. 35}

Se trata fundamentalmente del tramo de muro asociado a la construcción de los arcos 24 y 25. Lo constituyen bloques de piedra arenisca, caliza y de otros tipos, de tamaño mediano, ligeramente retocados en su cara externa, dispuestos en hiladas irregulares y unidos con mortero de cal bastante compacto que se extiende por la superficie del muro formando un revoque (fig. 17). Como estructuras asociadas presenta los arcos 24 y 25, así como el tajamar y el espolón del pilar de separación entre estos dos elementos.

Es probable que el arco 25, tal como ha llegado hasta nosotros, sea el resultado de una remodelación y que en un primer momento tuviera las mismas dimensiones que 24 (fig. 20). La parte superior de la estructura parece bastante homogénea des del punto de vista tipológico con los pilares que la sustentan, especialmente con el más oriental, que es común con el arco 24. A pesar de ello se detectan algunos detalles que ponen de manifiesto la remodelación a la que nos referimos. En primer lugar, el pilar de separación entre los arcos 24 y 25 presenta a ambos lados cinco encajes correspondientes a las vigas de soporte del andamio utilizado para su construcción, mientras que en el pilar occidental del arco 25 sólo aparecen dos de estos encajes y a diferente altura, cuando normalmente estos elementos de soporte son simétricos. Por otra parte la diferencia de medida entre los dos arcos parece reforzar tal hipótesis, ya que el arco mayor es el más alejado del cauce cuando seria más lógico lo contrario, si la construcción de ambos hubiera sido contemporánea. Finalmente, el basamento occidental de 25 no es uniforme sino que presenta un cierto engrosamiento en la parte más baja que podría corresponder al pilar del arco anterior.

Respecto a su posición física, el paramento u.e. 35 es claramente posterior a 21 y anterior o contemporáneo de 39 y correspondería, por lo tanto, a una cuarta fase constructiva del puente.

\section{Paramento u.e. 39}

Está formado por bloques de piedra de tamaño medianogrande, ligeramente retocados y unidos con mortero de cal. Forma hiladas muy irregulares en las que aparecen numerosas cuñas de piedra entre los bloques. Se diferencia con bastante claridad del paramento u.e. 35 aunque podrían corresponder a la misma fase constructiva. 

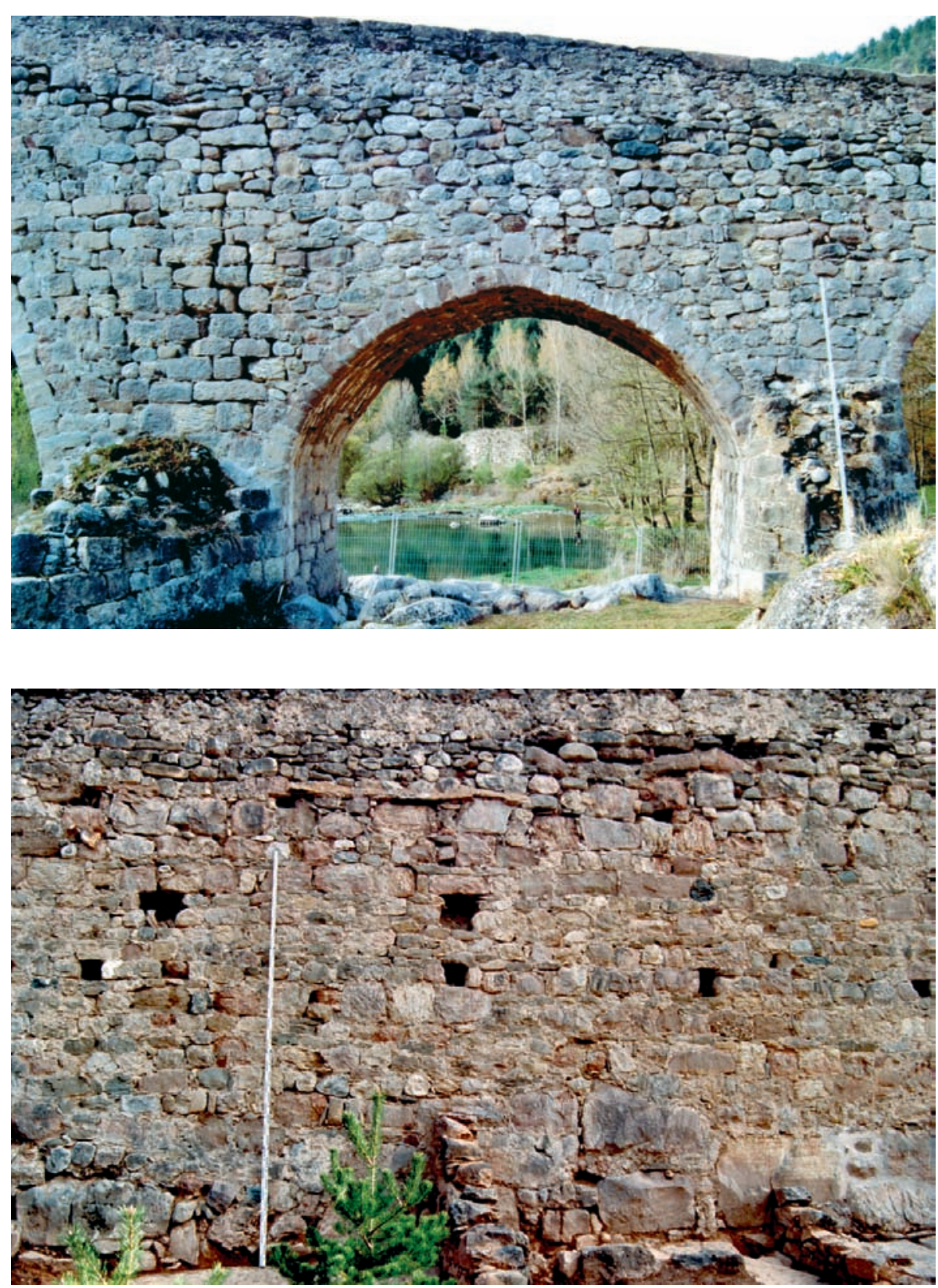

Fig. 17. Vista general del arco 24 y del paramento u.e. 35. Foto: Josep M. Vila, 2000. Archivo fotográfico SPAL

Fig. 18. Vista general del paramento u.e. 15. Foto: Josep M. Vila, 2000. Archivo fotográfico SPAL

\section{Paramento u.e. 15}

Corresponde a una gran reparación del sector más occidental del puente, al oeste del arco 25. Está formado por bloques medianos y grandes de piedra de diferentes tipos, muchos de ellos seguramente reutilizados, dispuestos en hiladas irregulares y unidos con mortero de cal muy abundante. Estratigráficamente es posterior a 39 y anterior a la construcción del pretil actual del puente.

\section{Paramento u.e. 19}

Se trata de una gran reparación situada en el tercio oriental del puente. Está formado por sillares de piedra reutilizados, bloques más pequeños y cantos rodados, dispuestos de manera aleatoria y unidos con abundante mortero de cal que sobrepasa las juntas y revoca parte de las piedras. Estratigráficamente es posterior a $21 \mathrm{y}$ anterior al pretil actual del puente. Tipológicamente la disposición de este paramento es bastante similar a 35 por lo que creemos que podrían corresponder a la misma fase constructiva.

\section{Paramento u.e. 40}

Se trata de una gran reparación situada en el extremo oriental del puente. Está formada por grandes bloques de piedra entre los que predominan los de perfil cuadrangular y que están dispuestos en hiladas irregulares en función del tamaño de los bloques. No tiene estructuras asociadas y 
estratigráficamente sólo sabemos que es posterior al paramento u.e. 1.

\section{Paramento u.e. 20}

Lo constituye el muro del pretil del puente. Mide 38 $\mathrm{cm}$ de anchura y está conformado por bloques medianos y pequeños de piedra, muchos de ellos cantos de río, unidos con abundante mortero de cal muy compacto. Está rematado por grandes bloques rectangulares de piedra arenisca y presenta una serie de agujeros para drenar el agua del pavimento del puente, del que parece ser contemporáneo. Se trata, en principio, de la estructura más moderna de las que constituyen la fachada meridional del cuerpo del puente.

\section{Descripción de la fachada norte (figs. 3 y 4)}

En el lado septentrional del puente aparecen de nuevo aproximadamente los mismos paramentos que en el lado sur aunque con algunas variaciones, tanto en su extensión como en su composición. En primer lugar no aparece el paramento u.e. 15 , lo cual demuestra que corresponde a una reparación de la fachada sur y no a una reconstrucción del puente. En este sentido en el lado norte el paramento 1 se conserva hasta casi el inicio del arco 25 .

Las únicas diferencias destacables se sitúan en el extremo oriental y están relacionadas con la construcción del contrafuerte u.e. 46 (fig. 19). En este punto se detecta un importante desplome de la fachada, tanto por el lado correspondiente al paramento u.e. 1 como al muro 21 . Ello supuso la aparición de una importante grieta en la unión entre los arcos 22 y 44, así como el derrumbe de la parte más alta de la fachada del puente en este sector. Este desplome parece que se trató de neutralizar con la construcción del contrafuerte. A pesar de ello el desplazamiento previo de la fachada era suficientemente importante como para que se tuviera que intervenir para repararla a través del muro 40 en el extremo más oriental y el paramento 41 en la parte alta. Éste último está formado por cantos de río y otros bloques medianos y pequeños unidos con mortero de cal y dispuestos en hiladas irregulares. Desde el punto de vista estratigráfico parece contemporáneo de la construcción del pretil actual del puente.

\section{CONCLUSIONES}

A partir de los resultados obtenidos en la intervención arqueológica que acabamos de describir, y con el complemento de algunas aportaciones documentales fruto de estudios precedentes, trataremos de desarrollar una hipótesis de evolución constructiva del puente de Pedret con sus

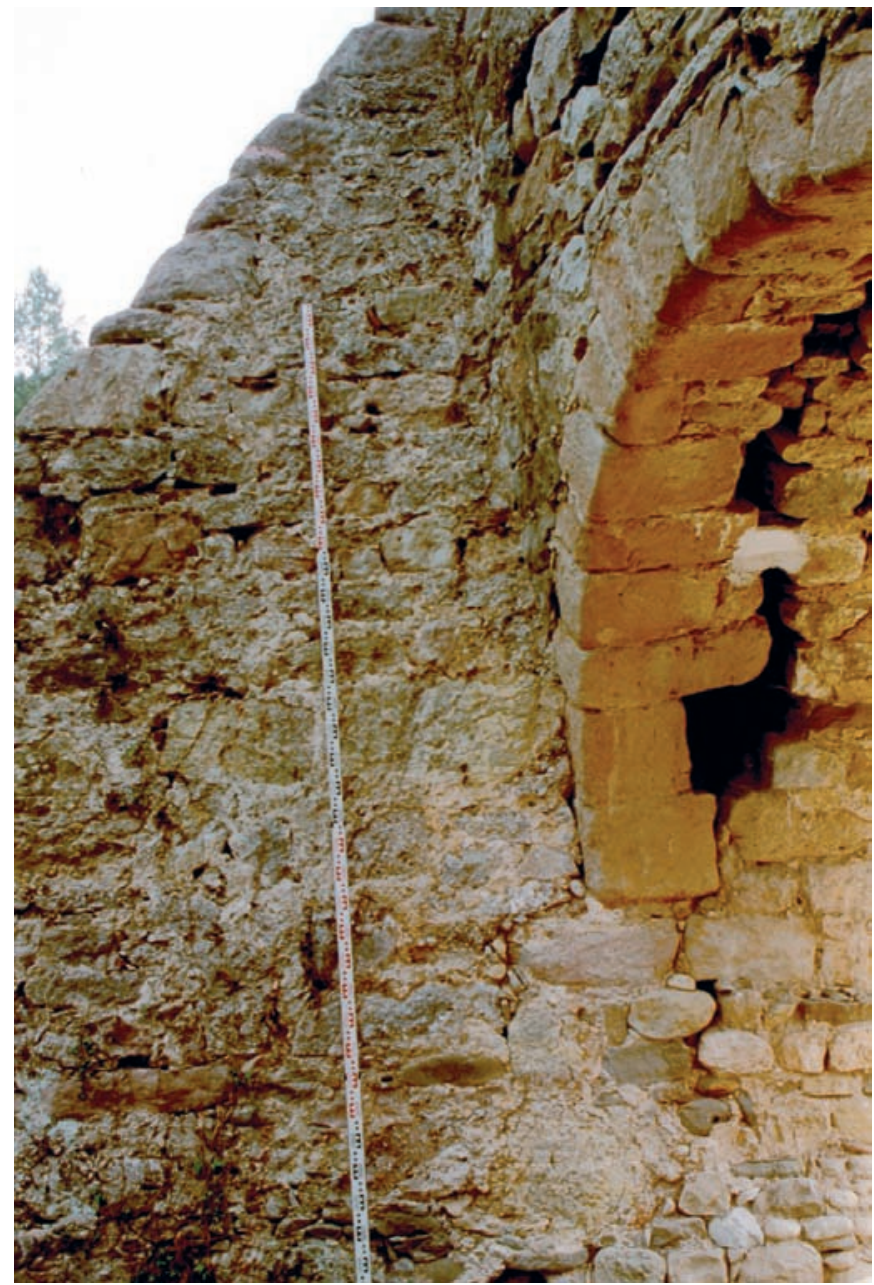

Fig. 19. Detalle del contrafuerte u.e. 46. Se observa como se apoya sobre un elemento preexistente que podría corresponder a un antiguo tajamar. Foto: Josep M. Vila, 2000. Archivo fotográfico SPAL

correspondientes atribuciones cronológicas y el contexto histórico en el que se desarrollaron. Hemos tratado también de estudiar, en la medida de lo posible, las interacciones entre el río y el puente, así como las mejoras constructivas que cada reparación aportaba.

\section{Precedentes (siglos IX-XI)}

Las primeras referencias al lugar de Pedret están fechadas en un momento impreciso del siglo IX y han de situarse en el marco del lento pero progresivo proceso de afianzamiento del poder condal en el sur y este de la comarca del Berguedà que se vio acelerado a finales de aquella centuria con el impulso dado por el conde de Barcelona Guifré el Pilós. En este período el territorio fue dotado de una estructura eclesiástica (se consagran en esta época un elevado número de iglesias) y de una ordenación civil y militar que permitió fijar la población preexistente y establecer las bases de la nueva estructura territorial y social 


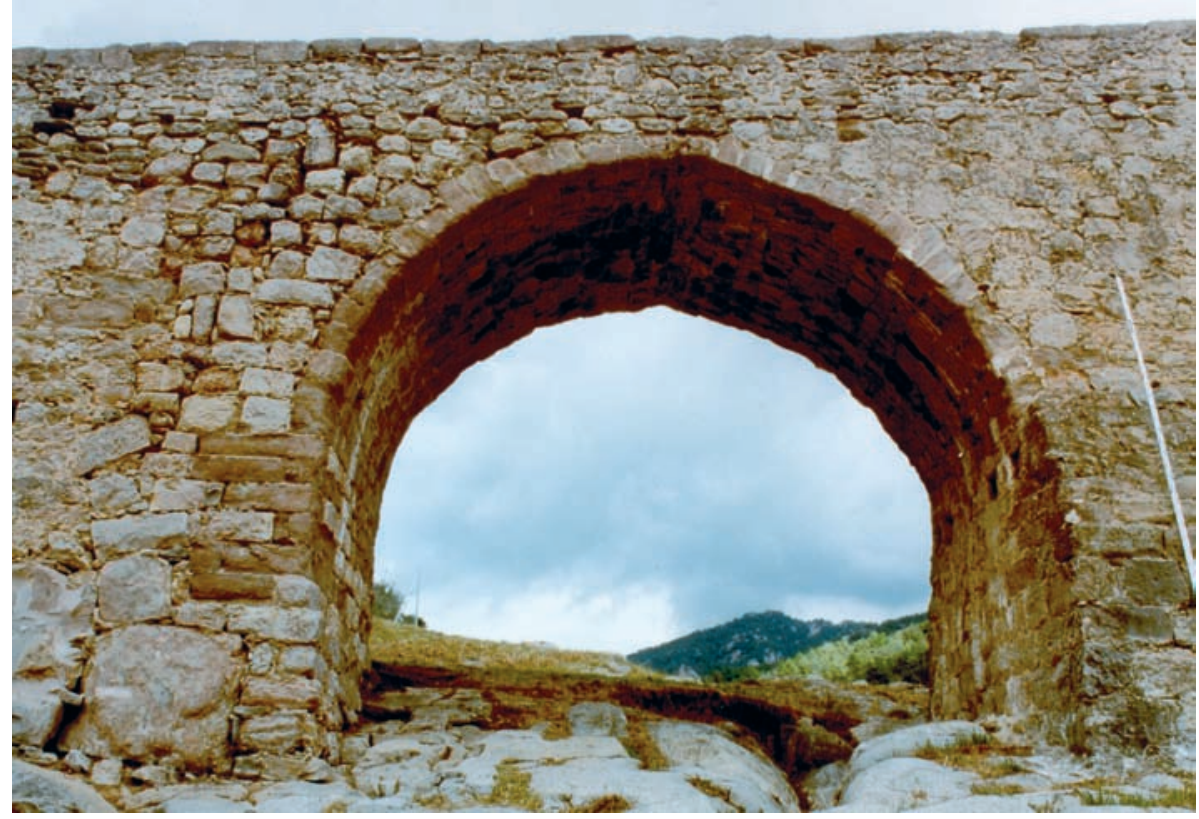

Fig. 20. Vista general del arco 25 tal como quedó tras la fase V. Foto: Josep M. Vila, 2000. Archivo fotográfico SPAL impulsada por las familias condales. Este proceso se fue consolidando a lo largo del siglo $\mathrm{x}$, como queda de manifiesto en las notables reformas que sufrió el cercano templo de Sant Quirze de Pedret en este periodo, y que han sido documentadas arqueológicamente (López-Caixal 1995). Todo ello parece indicar que durante el siglo XI el lugar de Pedret continuó aumentando y consolidando su población hasta conseguir la categoría de parroquia (Castellano 1995: 187).

Este proceso de ordenación del territorio debía llevar aparejada una dinámica de recuperación de caminos anti- guos y de creación de rutas de comunicación entre las nuevas fundaciones y entre éstas y los centros del poder administrativo y religioso. En este sentido, sabemos de la existencia, en el lado de levante del puente, de un camino que llevaba del monasterio de Sant Pere de la Portella, documentado desde finales del siglo x (Santamaría 1957), al núcleo de La Baells y que conectaba entre sí diversas poblaciones de la zona. Por su parte, en el lado occidental del río se encuentra la villa de Berga que desde el primer momento fue la sede de una de las unidades administrativas del territorio, el llamado condado de Berga, dependien-

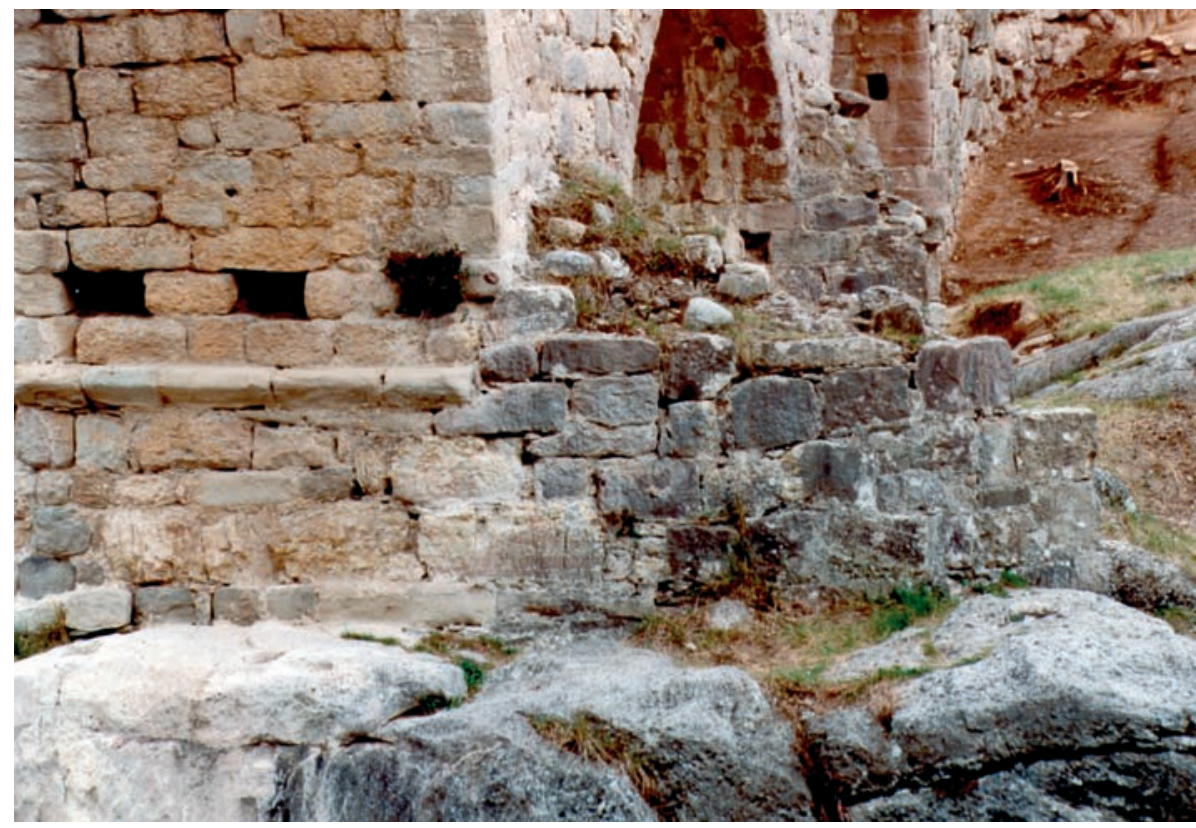

Fig. 21. Vista de uno de los tajamares de la cara norte del puente. Foto: Josep M. Vila, 2000. Archivo fotográfico SPAL 
te del de Cerdanya, y el principal centro de comunicaciones de la zona. La conexión natural entre Berga, la iglesia de Sant Quirze y el camino al que nos hemos referido que llevaba de La Baells a La Portella, se debía realizar a través de la zona del actual puente de Pedret. Es por ello que cabe pensar que a lo largo del siglo XI se fue incrementando progresivamente la importancia del paso de Pedret, especialmente para garantizar las comunicaciones entre las parroquias del lado este del Llobregat y la capital administrativa de la zona: la villa de Berga, situada en el margen occidental del río. Este camino, como la mayoría de las vías de comunicación medievales catalanas, se mantuvo en uso hasta mediados del siglo XIX cuando se inició la construcción de la moderna red de carreteras (Soldevila 1993: 320) y muchas de las antiguas vías dejaron de ser transitadas.

Los restos más antiguos que se conservan del puente corresponden a un paramento de grandes bloques de piedra que tipológicamente no parecen atribuibles a este primer período (figs. 12 y 14). Por otra parte, en la zona donde se asienta el actual puente, el lecho menor del río (aquel por el que circulan normalmente las aguas) discurre por una garganta relativamente estrecha y a la que se accede por una pendiente bastante suave. Estas características sólo se producen en este punto ya que hacia el norte la garganta es mucho más alta y aguas abajo el río se abre notablemente. Estas características hacen de este punto el paso natural del Llobregat entre Berga y Pedret. Por otra parte estas mismas características del sector provocaban que fuera relativamente sencillo colocar una pasarela de madera para pasar el río. Resulta evidente que un puente de estas características debía desaparecer con relativa facilidad a cada crecida importante, pero también era fácilmente restituible.

Sabemos, por otra parte, por las diferentes alineaciones de orificios de poste que se documentan en las afloraciones rocosas situadas en el lado oriental del puente, que existía una notable actividad constructiva en el entorno del Llobregat en este punto. Tradicionalmente se ha considerado que estas alineaciones corresponden a una o sucesivas presas construidas para desviar las aguas hacia un molino que se encuentra un poco más abajo (Bolòs 1985). En todo caso, hay diversos agujeros a ambos lados de la garganta que se podrían relacionar más bien con los primeros puentes de madera.

En definitiva, consideramos que en un primer momento la solución del paso del río Llobregat en este punto se resolvió con pasarelas o puentes de madera que permitían asegurar una circulación más o menos estable. De todos modos, esta solución era insegura a causa del régimen de crecidas del Llobregat y se volvió cada vez más incómoda a medida que iba en aumento la circulación en la zona. Por ello debió hacerse evidente muy pronto la necesidad de construir un puente de mayor solidez.

\section{Fase I (siglos XI-XII/XIII)}

El primer puente que se construyó en Pedret y que se asocia al paramento u.e. 1 debía estar formado por tres arcos, de los que sólo se ha conservado la parte interna del más oriental, así como los restos del espolón situado en la base del pilar de separación entre el arco central y el más occidental. Si generalizamos la técnica constructiva del arco que se ha conservado, hemos de suponer que las impostas estarían construidas con bloques de piedra de tamaño mediano, mientras que la parte superior se levantaría con piedras más pequeñas y cantos de río partidos, colocados según la técnica habitual en las bóvedas de cañón. El remate exterior del arco, que posteriormente fue sustituido (fig. 15), estaría seguramente formado por una alineación de losetas irregulares, similar a la que presenta el cercano puente de la Farga Vella en Castellar de n'Hug (Maristany 1998: 167), aunque este último seguramente de cronología algo posterior.

La atribución que hacemos de este arco a la primera fase, aunque no disponemos de una relación física directa entre la parte conservada del arco y el paramento correspondiente en la fachada, se basa en que la tipología de esta estructura es completamente distinta del resto de arcos y especialmente de los que se vinculan a la fase II. Por otra parte, el sistema constructivo detectado en este arco es más arcaico y por ello más fácilmente atribuible a la primera fase de funcionamiento del puente.

No se puede descartar la existencia de un cuarto ojo del puente al este del mencionado ya que en la base oriental del arco, aguas arriba, aparecen unos bloques de piedra que insinúan un antiguo tajamar por encima del cual se construyó un contrafuerte. Si realmente existió, debía ser muy pequeño y probablemente tenía más bien una función de aliviadero. Desconocemos la altura exacta del puente en esta fase, pero parece probable que fuera más bajo que el actual aunque de tipología similar puesto que el arco central había de ser marcadamente más alto que los demás, aunque todavía de medio punto. La pavimentación no se ha conservado, pues fue destruida a lo largo de las sucesivas transformaciones de la estructura, aunque no se puede descartar que se conserve algún tramo dentro de la caja del puente en zonas no excavadas.

De la estructura del elemento en esta primera fase se desprende que las aberturas más importantes se realizaron en el lado oriental del río, que corresponde al sector más 


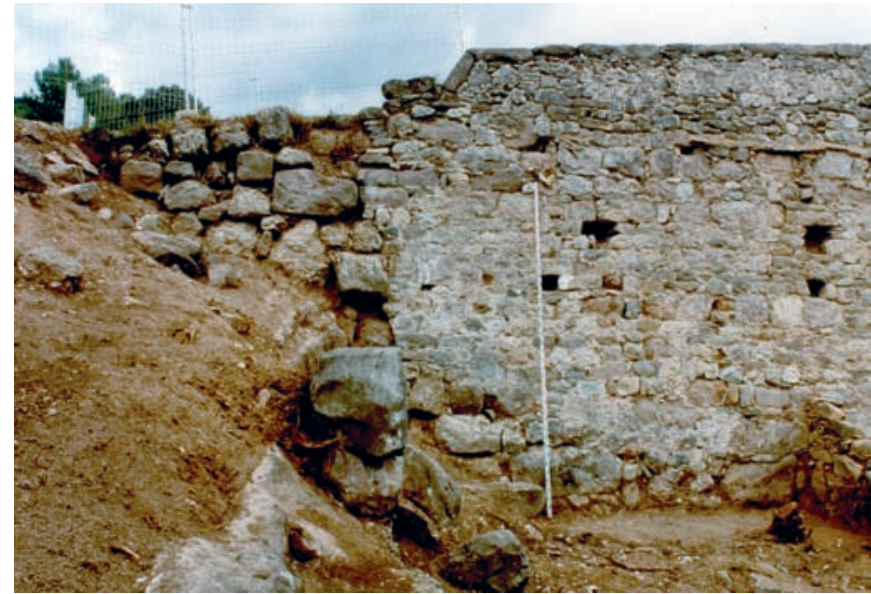

Fig. 22. Vista del estribo sur oeste del puente. Foto: Josep M. Vila, 2000. Archivo fotográfico SPAL

afectado por las crecidas de pequeña y mediana intensidad, ya que el costado oeste está más protegido por la ladera de la montaña. Esta solución permitió construir un puente de una longitud relativamente grande con una mínima complejidad constructiva y por tanto con un coste también menor. Por contra, este sistema hace más débil la estructura en caso de grandes avenidas, en las que el agua supera el espigón de roca que protege el puente por el lado occidental y éste recibe todo el impacto de la crecida sobre la caja, puesto que en ese costado no hay arcos que permitan la evacuación de las aguas. En estos casos la mayor incidencia del agua se produciría contra la base occidental del arco central que parece que fue el que sufrió de manera más intensa los efectos de las crecidas en los primeros tiempos de funcionamiento del puente. Es muy probable que en uno de estos episodios se produjera su hundimiento.

Sobre la cronología de esta primera fase no disponemos de elementos claros para hacer una propuesta categórica. Tipológicamente, puentes como el de Pedret los encontramos en toda la zona ya en época románica con cronologías que oscilan entre los siglos XI y XII. Sería el caso del puente viejo de Guardiola (Bolòs 1985b), puente del Far (Viladés 1985) o el puente viejo de Gironella (Maristany 1998: 177). En todo caso, el tipo de paramento que encontramos en esta primera fase de Pedret no tiene paralelos en ninguno de ellos, en general construidos con bloques mucho más pequeños. Es posible que esta particular composición se debiera a la existencia de tramos importantes del puente sin arcos. Ello pudo provocar un reforzamiento de la estructura constructiva de la caja a base de utilizar bloques de mayor tamaño que a priori pudieran soportar mejor el impacto del agua. Finalmente, la técnica utilizada para construcción de la bóveda del arco conservado parece propia de los siglos XI-XII.
La excavación arqueológica de los sedimentos adosados a los muros del puente no aportó materiales significativos y los niveles en los que se recuperaron cerámicas medievales no estaban en contacto directo con él. En cualquier caso, la cronología de estas cerámicas, atribuibles al cercano taller de Casa-en-Ponç (Padilla 1983-1984), corresponde a un período relativamente extenso que va desde la segunda mitad del siglo XII hasta finales del XIII (López, Caixal, Fierro 1997), por lo que podrían estar asociadas tanto a la primera como a la segunda fase del puente. Así pues y aunque sin poder precisar demasiado, entendemos que podemos situar esta primera fase del puente en un momento incierto entre los siglos XI y XII, especialmente al largo de esta segunda centuria.

\section{Fase II (finales del siglo XIII - siglo xv)}

En un momento que no podemos determinar con precisión, pero que probablemente habría que situar a finales del siglo XIII, se produjo el hundimiento parcial del puente que afectó básicamente al arco central y a los arranques de los arcos laterales. No sabemos cuánto tiempo estuvo fuera de uso (provisionalmente, el paso del río se podía hacer, como al principio, a través de una pasarela de madera), aunque no creemos que fuera mucho. Tenemos noticia de un testamento fechado en 1286 por el cual Ramón de Avià donaba dinero para operis ponte de Pedreto. Este personaje era miembro de una familia noble afincada probablemente en Berga y que tenía posesiones en la zona de Pedret, por lo que estaría directamente interesado en conservar la comunicación directa con las mismas (Castellano 1995: 190).

También a finales del siglo XIII se produce la reconstrucción de la iglesia de Sant Quirze de Pedret que había sido parcialmente destruida por un incendio y que fue objeto de importantes transformaciones (López, Caixal 1995: 224). Finalmente, a mediados del siglo XIII el rey inició un proceso de compra de tierras en la zona que continuará a principios del siglo XIV. Así pues, parece probable que se pueda situar en este momento de finales del siglo XIII la reconstrucción del puente y por tanto el inicio de esta segunda fase. Esta cronología también podría coincidir con la datación de las cerámicas grises recuperadas durante la excavación en las inmediaciones de la estructura.

En aquel momento parece que se levantaron de nuevo los arcos central y occidental, presumiblemente con perfil de medio punto y de los que se ha conservado el arranque oriental (u.e. 34). El pilar entre estos dos arcos se construyó sobre la base del anterior, añadiendo un tajamar en el lado norte pero manteniendo el espolón de la fase anterior. También se remodeló el ojo oriental del puente con la 
Fig. 23. Vista general del arco central del puente. Foto: Josep M. Vila, 2000. Archivo fotográfico SPAL

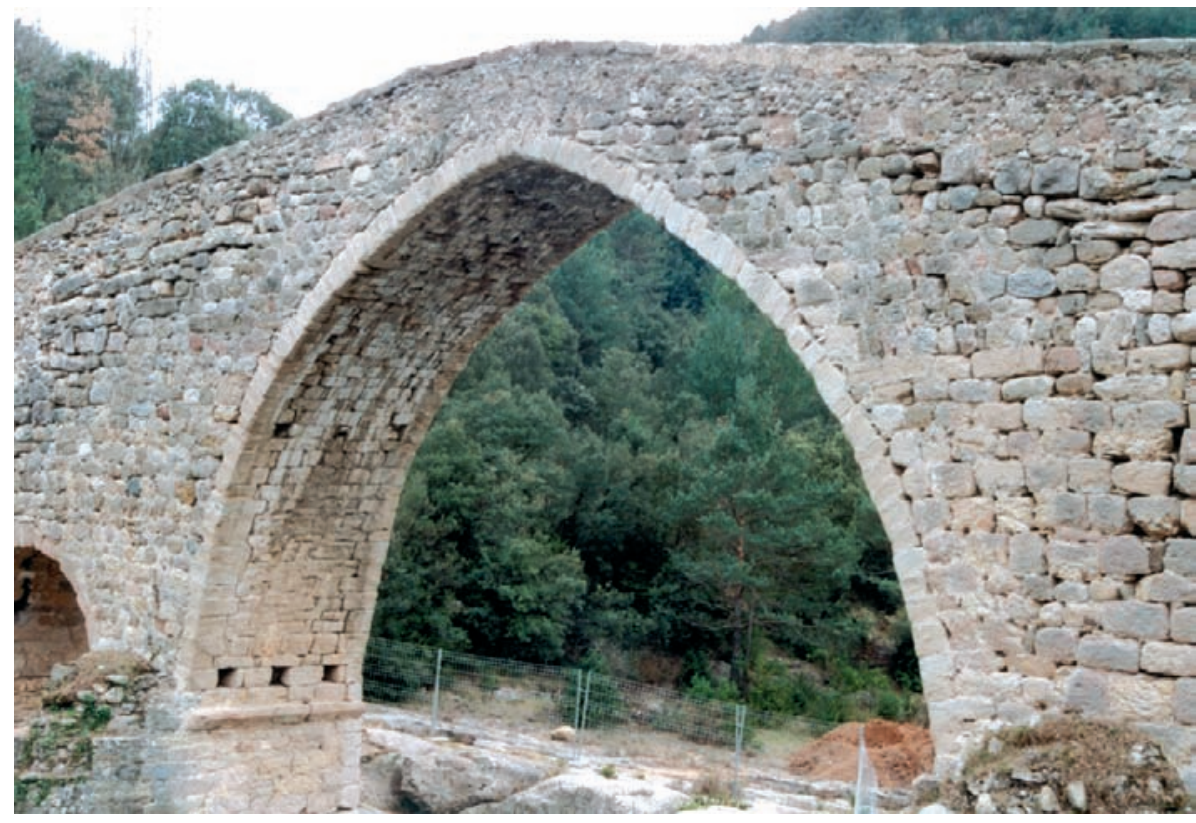

colocación de una nueva rosca (fig 15). Coincidiendo con estas obras, se reconstruyó una parte de la fachada meridional al este del arco, probablemente sellando el hipotético aliviadero de la fase anterior.

El paramento asociado a esta fase es muy característico y está constituido por sillarejo de piedra arenisca rojiza o clara dispuesto en hiladas regulares (figs. 15-16). Las dovelas de los arcos de esta fase también presentan una mayor regularidad y están talladas en el mismo material. La técnica constructiva de las bóvedas de los arcos también cambia respecto a la fase anterior y encontramos una mayor regularidad en el aparejo, hecho de sillarejo, en la totalidad del perfil de la bóveda. Desconocemos por completo las características del pavimento del puente ya que se encontraba en una cota inferior a la del actual y en buena parte desapareció en el marco de reformas posteriores.

En esta fase Pedret adquiriría una imagen similar, salvando las distancias en cuanto a las dimensiones, a muchos de los grandes puentes góticos de su entorno como el puente viejo de Manresa (Maristany 1998: 194), el Pont Trencat de Cardona (Maristany 1998: 198). Otros de cronología similar y que han sido objeto de estudios históricos y arqueológicos específicos por parte del Servei del Patrimoni Arquitectònic Local de la Diputación de Barcelona son los de Castellbell (Caballero 1991), Avinyó (Lacuesta 2006) y Periques (Macià 1993 y 1996). Pocos kilómetros río abajo de Pedret, en el cercano núcleo de Olvan, se encuentra el puente viejo de Orniu cuya construcción se situa hacia finales del siglo XIV y que presenta un aparejo tam- bién bastante regular, aunque con sillares de mayor tamaño que el de Pedret (Caixal, Galí 2006).

Parece ser, por lo tanto, que la reconstrucción del puente repitió el esquema de la estructura original, sin que aparentemente se construyeran más arcos en el lado occidental. Ello comportó que se continuaran manifestando los mismos problemas de resistencia del puente ante las crecidas de carácter excepcional. El hecho de que no se solucionaran estas cuestiones de base provocó, en un momento de difícil precisión cronológica, el segundo derrumbamiento de la estructura, que se generó en los mismos puntos que el primero y provocó la caída del arco central. En este caso, sin embargo, la destrucción no fue tan importante ya que no afectó a los arcos laterales. La cronología de este acontecimiento viene determinada por dos elementos complementarios. El primero, y más importante es la atribución a finales del siglo XV del arco ojival que determina la fase III. Un segundo aspecto es el conocimiento que tenemos a través de la documentación escrita (Solé 1983: 21) de que a finales del siglo XV se produjo una importante crecida en la zona del Berguedà que podría haber originado la destrucción del puente.

\section{Fase III (finales del siglo XV)}

Esta fase viene determinada por la reconstrucción del ojo central del puente con el arco ojival que se conserva actualmente (fig. 23). La cronología de este elemento es difícil de precisar aunque otros arcos similares en puentes del entorno como el del puente viejo del Pont de Vilomara, se ha podido fechar a finales del siglo XV (VVAA 1995: 91). Se trata 
de una estructura de $12,5 \mathrm{~m}$ de luz y rematada con una rosca de dovelas de piedra arenisca clara unidas con mortero de cal. En su intradós presenta dos líneas superpuestas de orificios asociados al andamio utilizado en el momento de su construcción. Parece que el resto de los arcos del puente se mantuvo en funcionamiento, y sólo se reconstruyó o añadió el tajamar situado en el pilar oriental del arco central.

Es muy conocida la teoría clásica de Carlos Fernández Casado sobre el origen del uso del arco ojival en los puentes como resultado de la experimentación de sus constructores (Fernández 1982). Últimamente algunos autores han matizado esta interpretación para el caso de arcos con apuntamiento importante como sería el de Pedret ya que, en el caso de los puentes, un arco ojival no ofrece mayor resistencia a las cargas que uno de perfil más rebajado (Fernández 2005: 24). Esta constatación técnica abre la puerta a consideraciones más estilísticas por lo que se refiere a la elección de este tipo de arco. En este sentido, algunos autores han considerado el arco ojival como el elemento que caracteriza el paso del románico al gótico en la arquitectura de los puentes, situándolos entre los siglos XIII y XV (Fernández 1982). En nuestro caso, su construcción hacia finales del período demuestra una vez más la perduración del uso de este elemento más allá de la edad media, situación claramente documentada también en otras edificaciones de la arquitectura, sobre todo, civil, por lo menos en Cataluña.

Asociado a este momento constructivo documentamos un paramento formado por bloques de piedra de distintos tipos, tanto sillarejos de arenisca o conglomerado, como cantos de río partidos, todos ellos dispuestos en hiladas irregulares y unidos con mortero de cal muy compacto (fig. 13). Esta composición indica que se construyó en buena parte aprovechando bloques antiguos que se recolocaron, completándose el paramento con los grandes cantos de río. Desconocemos el tipo de pavimento asociado a esta fase ya que no se han realizado excavaciones arqueológicas en la zona del arco central. En cualquier caso lo más probable es que se tratara de un nivel de cantos rodados de diferentes tamaños unidos con mortero.

\section{Fase IV (Siglo xVI)}

La construcción de un ojo central de mayor altura debió atenuar parcialmente la presión sobre el puente durante las avenidas de carácter excepcional, lo que ha propiciado su conservación hasta hoy. De todos modos, parece que relativamente pronto se hizo evidente la necesidad de hacer nuevas reformas que permitieran asegurar la solidez del puente ante grandes crecidas. Para ello se optó por cons- truir dos nuevos ojos en el lado occidental que permitieran aliviar la presión del agua.

Esta intervención, sin duda importante, contrasta con la aparente decadencia que vivía el término de Pedret a principios del siglo XVI. Tal situación queda claramente reflejada en un documento fechado en 1510 que definía la parroquia de Pedret como inhabitata et carens parrochianis, situación que se verá confirmada a finales de siglo en una visita pastoral (Castellano 1995: 192). Parece que durante este período el área de Pedret se convirtió en zona de pastos controlada por los barones de Peguera. Este hecho, junto con la vigencia de la necesidad de paso entre Berga y el otro lado del río Llobregat, podría explicar el interés por la mejora de las condiciones constructivas del puente.

Así pues, atribuimos a esta fase la construcción de los dos arcos más occidentales de la estructura. Para su realización se tuvo que derruir un tramo del puente antiguo hasta el arranque del arco 34 (el más occidental hasta entonces) y se construyeron dos nuevos de medio punto rebajado (fig. 17 y 20), separados por un pilar de 2,3 $\mathrm{m}$ de anchura, muy consistente y provisto de tajamar y espolón. Los arcos estaban conformados por una rosca de bloques de piedra arenisca rojiza. La solidez constructiva de estos arcos y pilares, hechos con sillares, contrasta con los muros de mampostería que se les asocian y con el que está construida la caja del puente sobre los arcos.

En esta fase los dos arcos debían tener las mismas dimensiones y posteriormente se produjo la remodelación del más occidental. Entonces el puente ya tendría los cuatro ojos actuales que habrían permitido paliar de manera satisfactoria la acción sobre el mismo de las grandes avenidas del Llobregat. Respecto al pavimento, es posible atribuir a esta fase el que se documentó por debajo del actual en la intervención arqueológica realizada en 1993. Según consta en el informe de aquella excavación (López, Caixal 1993), este pavimento inferior estaba compuesto por cantos rodados de tamaño relativamente grande, dispuestos horizontalmente y unidos con mortero de cal. El hecho de que el sondeo se realizara en el sector del puente situado entre los arcos más occidentales no había permitido detectar las modificaciones, si las hubo, de este pavimento en el momento de la reconstrucción del arco 25. Desgraciadamente el escaso alcance de aquella intervención no permitió en su momento obtener datos fiables sobre la cronología del pavimento, que habrían sido muy útiles para la datación de esta fase. Cabe añadir que también podría corresponder a este horizonte cronológico una importante reparación detectada en la fachada meridional del puente (en el lado este) y definida por el muro 


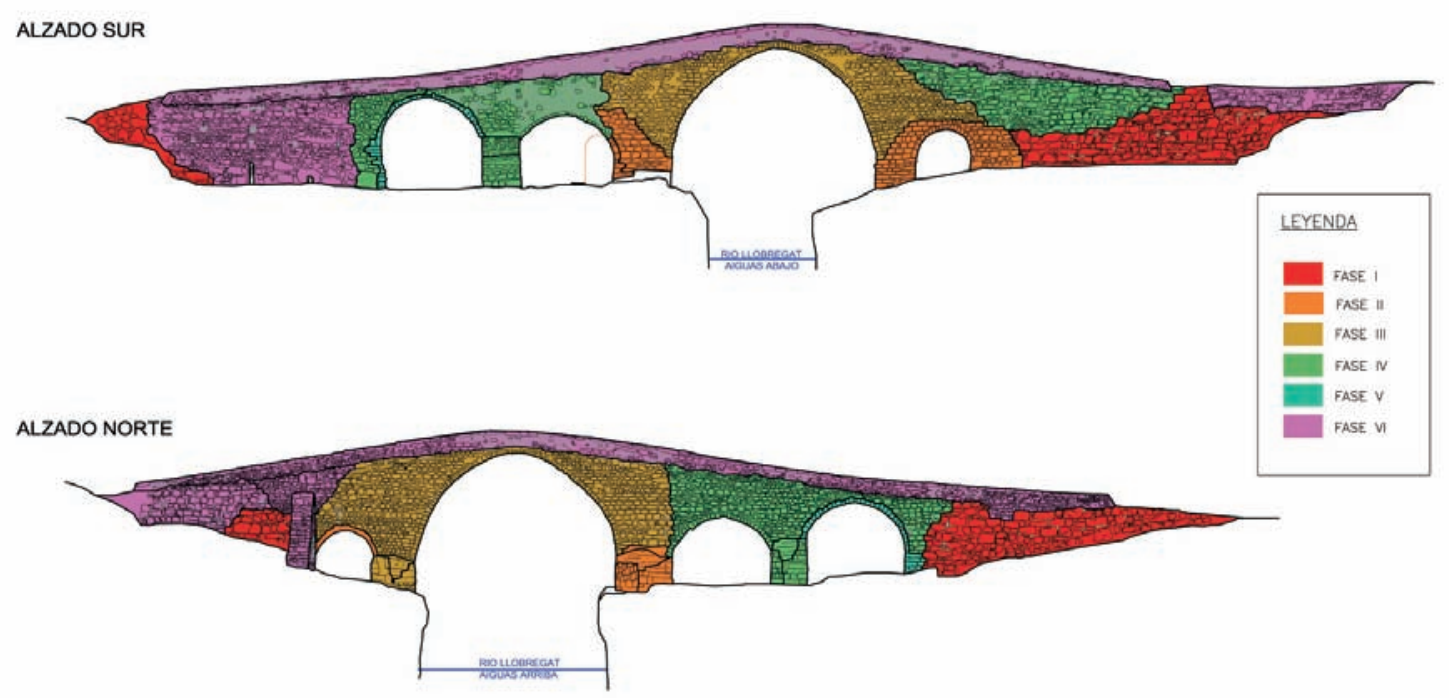

Fig. 24. Alzados norte y sur del puente con indicación cromática de las fases constructivas

de paramento aleatorio cuya fábrica es muy similar a la del muro asociado a los dos arcos de esta fase.

\section{Fase V (Siglos XVI-XVII)}

Correspondería a este momento el recrecimiento del arco 25 que se podría haber realizado sin desmontar la parte superior del puente, ampliándose tal abertura por debajo. Tal solución explicaría que no se recreciera la pared del puente a pesar de que la parte alta del nuevo arco queda muy cerca de la superficie del elemento. Si se confirmara esta hipótesis, el pavimento que se utilizaba entonces sería el mismo de la fase anterior, con su correspondiente pretil, que ya fue también detectado en el transcurso de la excavación de 1993 (López, Caixal 1993).

\section{Fase VI (Siglos XVII-XVIII)}

Situamos en esta fase las últimas reparaciones conocidas del puente y que están constituidas por la construcción del muro 15 en el tramo más occidental de la fachada sur y por una serie de reparaciones en el extremo oriental, especialmente en la fachada norte, a las que se asocia la construcción de un contrafuerte. Resulta difícil determinar si estas dos intervenciones son contemporáneas o se realizaron en momentos diferentes. Lo que sí queda claro, y por este motivo las hemos incluido en la misma fase, es que todas ellas son anteriores o contemporáneas de la colocación del pavimento y del pretil actuales del puente.

La construcción del muro 15 parece ser una simple reparación de un tramo de la fachada meridional, sin más implicaciones (fig.18). En cambio, la intervención del lado oriental supuso una actuación más compleja. El proceso que llevó a la necesidad de construir el contrafuerte tenía, sin duda, un origen antiguo aunque debió manifestarse de manera progresiva. El lado septentrional del puente es el que recibe de una manera más intensa la acción erosiva, no sólo de las riadas sino también de los agentes meteorológicos. Así, la lluvia moja siempre las paredes verticales del puente que retienen mucho más tiempo la humedad a causa de la menor insolación. El agua es absorbida por la piedra y los morteros, lo que provoca un proceso de degradación lento pero inexorable que se acelera con la acción del frío. Las heladas provocan un aumento del volumen que rompe por sobrepresión la red porosa de las piedras y de los morteros, produciendo una degradación más homogénea por toda la superficie afectada. Como consecuencia de estos procesos se desprenden los morteros de las juntas, quedando los sillares sin unión, facilitando de esta manera que se desplacen hasta llegar a desprenderse ${ }^{4}$.

Estos procesos afectaron sin duda la totalidad de la fachada norte, pero lo hicieron de una manera especial en el lado más oriental, al tratarse de un sector mucho más umbrío y afectado por la acción del viento que sopla acanalado siguiendo la garganta del río. Este hecho provocó el desplazamiento progresivo del lienzo exterior del puente en este sector, como lo demuestra el hecho de que los restos del muro original que se han conservado in situ tengan un desplome considerable y que el arco y el paramento que se le asocia aparezcan claramente separados del núcleo del puente. Este desplome debió aumentar hasta el punto de provocar el desprendimiento parcial del pretil y tal vez de una parte de la fachada. Una situación

${ }^{4}$ Ver al respecto, el informe del arquitecto técnico Josep M. Moreno en: Restauració del Pont de Pedret. Documentació previa. Octubre 1993, Servei de Patrimoni Arquitectònic Local, Diputació de Barcelona (inédito). 
similar afectaba al extremo más oriental de la fachada sur. Ante esta situación, y con el objetivo de detener el desplazamiento del muro, se optó por la construcción del contrafuerte (fig. 19) que debía detener el desplome. Por otra parte se desmontó y reconstruyó a plomo el tramo más oriental del muro y se reconstruyó la parte caída. La obra se completó con la construcción de un nuevo pretil y la colocación de un último pavimento de cantos rodados (fig. 8).

La estructura del puente que se conforma tras estas reformas es básicamente la que se conservaba en el momento de iniciar las obras de restauración. En cuanto a la cronología de esta fase no disponemos de datos directos. Sabemos, eso sí, que la fase culmina con la colocación del pavimento del puente, que tiene un paralelo claro en el puente viejo de Castellbell i el Vilar, donde fue fechado entre los siglos XVI y XVII (Caballero 1991: 149). Por otra parte, sabemos a través de las fuentes documentales que el término de Pedret inició una fase de recuperación demográfica a partir de finales del siglo XVII, coincidiendo con un período de crecimiento económico generalizado en toda Cataluña. Este aumento de la actividad en la zona podría estar en el origen de la necesidad de consolidar un puente que parecería estar saliendo de un largo período de abandono relativo.

\section{Fase VII (finales del siglo xIX- inicios del siglo $\mathrm{xx}$ )}

Con posterioridad a las intervenciones descritas al tratar de la fase anterior no se detecta ninguna otra reparación importante de la fábrica del puente, que parece haber resistido sin grandes problemas todas las crecidas del Llobregat hasta la construcción, avanzado el siglo XX, del embalse de La Baells que regula la parte alta de su curso, haciendo desaparecer el riesgo de crecidas.

Sólo podemos atribuir a este período la construcción de las estructuras adosadas a la fachada meridional del puente. Se trata de una barraca en la que se aprecian dos fases constructivas sucesivas, probablemente con un corto periodo de abandono intermedio (fig. 11). La presencia en sus niveles de uso de objetos de hierro como cuñas, grandes clavos, una piqueta, etc, nos lleva a plantear que se trate de estructuras asociadas a la construcción o al mantenimiento de la línea ferroviaria que pasaba junto al puente. En este caso habría que situar la edificación del primero de los cobertizos hacia 1902-1903, momento de construcción del tramo cercano a Pedret de la línea de tren OlvanGuardiola (Camprubí 1996). Una vez concluidas las obras, la cabaña debió quedar en desuso y se derrumbó. Sabemos por una fotografía del año 1905 que en aquella fecha ya estaba construido el segundo cobertizo, que ya no aparece en una imagen de $1928^{5}$.

\section{Bibliografía}

Bolòs, J. 1985. "Rescloses de Pedret». Catalunya Romànica XII: El Berguedà. Barcelona: 236-238.

Bolòs, J. 1985b. «Pont Vell de Guardiola». Catalunya Romànica, vol. XII: 286.

Caballero, M. 1991. "L'evolució històrica del pont vell de Castellbell i el Vilar». Quaderns Cientifics i Tècnics, 3: Actes del Simposi Actuacions en el patrimoni edificat medieval i modern (segles X al XVIII): 146-152.

Caixal, A. 1996. "Intervencions arqueològiques en diversos ponts de la conca del riu Llobregat". Quaderns Científics i Tècnics, 8: Estudis informes i textos del Servei de Patrimoni Arquitectònic Local: 373-384.

Caixal, A. - Galí, D. 2006. «Pont Vell d'Orniu. Olvan». En: Conservació preventiva: última etapa. Memòria del SPAL 1999-2001: 41-46.

Camprubí Plans, J. 1996. «El ferrocarril a la Catalunya Central». (Manresa), Dovella, 53: 35-42.

Castellano, A. 1995. «Església de Sant Quirze de Pedret, Cercs. Les fonts documentals». Quaderns Científics i Tècnics, 6: Investigacions arqueológiques $i$ històriques al Berguedà (II): 183-194.

Fernández Casado, C. 1982. Historia del puente en España. Madrid.

Fernández Troyano, L. 2005. «Variantes morfológicas de los puentes medievales españoles». Revista de Obras Públicas, no 3.459: 11-32.

Lacuesta,R. - Vilamala, I. 2006. «Pont Vell. Avinyó». En: Conservació preventiva: última etapa. Memòria del SPAL 1999-2001: 23-30.

López Mullor, A.; Caixal, A. 1993. Informe preliminar dels sondatges realitzats al pont de Pedret (Berga-Cercs) el dia 16 de març de 1993. Servei del Patrimoni Arquitectònic Local de la Diputació de Barcelona (inédito).

López Mullor, A.; Caixal, A. 1995. «Església de Sant Quirze de Pedret, Cercs. Excavacions arqueològiques. Campanyes 1989-1992». Quaderns Cientifics i Tècnics, 6: Investigacions arqueológiques $i$ històriques al Berguedà (II): 194-359.

López Mullor, A.; Caixal, A.; Fierro,X.. 1997. «Cronologia i difusió d'un grup de ceràmiques medievals trobades a les comarques de Barcelona (segles VIIXIV)». Quaderns Cientifics i Tècnics, 9: Ceràmica Medieval Catalana. Actes de la Taula Rodona celebrada a Barcelona entre els dies 15 i 16 de novembre de 1994: 101-142.

Macià Bigorra,T. 1993. El pont de Periques de Puig-Reig: estudi documental, històric $i$ artístic. Barcelona.

Macià Bigorra,T. 1996. "Estudi documental, històric i artístic del Pont de Periques de Puig-reig». Quaderns Científics i Tècnics 8: Estudis, informes i textos del Servei del Patrimoni Arquitectònic Local: 5-38.

Maristany, M. 1998. Els ponts de pedra de Catalunya. Barcelona.

Padilla, J.I. (1983-1984) "Contribución al estudio de las cerámicas grises catalanas de época medieval: el taller, los hornos y la producción de Casampons». Barcelona. Acta Mediaevalia. Annex II. pp. 99-143.

Restauració del Pont de Pedret. Documentació prèvia. Servei del Patrimoni Arquitectònic Local de la Diputació de Barcelona (inédito).

Santamaría, J. 1957. Memòries del monestir de Sant Pere de la Portella i de tot el seu abadiat $i$ baronia. Solsona.

Solé, C.; Lapuerta, M.; Gallet, J. 1983. «Situació històrica de la riuada del novembre».(Berga). L'Erol, 4: 20-21.

Soldevila, T. 1993. "El pont vell de Roda de Ter. Estudi històric». Quaderns Cientifics $i$ Tècnics, 5: Estudis informes $i$ textos del Servei de Patrimoni Arquitectònic Local: 315-330.

Viladès, R. - Bolòs, J. 1985. «Pont del Far». Catalunya Romànica, vol. XII, p. 209.

VV.AA. 1995. Pont de Vilomara o Pont Vell. Pont de Vilomara-Manresa. Memòria del Servei del Patrimoni Arquitectònic Local 1990-1992: 85-97.

Recibido: 23 de agosto de 2009

Aceptado: 19 de octubre de 2009

5 Archivo Fotográfico del Servei de Patrimoni Arquitectònic Local. Fondo SCCM. Ficha número 16.578 . 